\title{
La relación trinitaria en santo Tomás de Aquino según los escritos Scriptum super libros Sententiarum, Summa contra gentiles, Compendium Theologiae y De potentia Dei
}

\author{
The Trinitarian Relationship in Saint Thomas \\ Aquinas, according to the writings Scriptum \\ super libros Sententiarum, Summa contra gentiles, \\ Compendium Theologiae, and De potentia Dei
}

\author{
Gabriel Sánchez García \\ Facultad de Teología San Isidoro de Sevilla \\ Sevilla. España \\ gabrieldelatorredelareina@yahoo.es \\ ID ORCID 0000-0002-3911-3091
}

\begin{abstract}
Resumen: Las relaciones distinguen a las personas divinas; así pues, la inteligencia teológica de las personas está basada en la propia relación, puesto que la "veritas fidei" implica que la única distinción que hay en Dios se toma de las relaciones reales de oposición, a saber: paternidad, filiación, espiración y procesión. Hemos querido realizar un acercamiento propio a partir de las obras de santo Tomás de Aquino propuestas en el título.
\end{abstract}

Palabras clave: Santo Tomás de Aquino, Trinidad, relación

\begin{abstract}
The relations distinguish divine persons; therefore, the theological intelligence of persons is based on the relationship itself since the "veritas fidei" implies that the only distinction that exists in God is taken from the real relations of opposition: paternity, filiation, spiration and procession. We wanted to make our own approach from the works of St. Thomas Aquinas proposed in the title.
\end{abstract}

Keywords: St. Thomas Aquinas, Trinity, relation

Dios, que es uno en cuanto esencia divina, es comprendido como el subsistens distinctum simpliciter. Propiamente así es entendido por santo Tomás de Aquino (1225-1274). Con el fin de guardar coherencia con la insoslayable, por revelada, existencia en Dios de una pluralidad de personas, coloca en el centro de su reflexión teológica las relaciones trinitarias. Estas entran de lleno en el significado de persona divina en cuanto que las define como relationem ut subsistentem. Retoma y supera el Aquinate las 
enseñanzas de san Agustín, puesto que para el Hiponate la relación es lo que diferencia a una persona divina de la otra y la constituye como tal en su distinción. Precisamente será este nuestro objeto de estudio: las relaciones trinitarias según la presentación que realiza nuestro Angélico a lo largo de sus escritos. Hemos acotado el campo de nuestro estudio a cuatro obras tan geniales como diferentes: Scriptum super libros Sententiarum o Scriptum super Sententiis, Summa contra gentiles, Compendium Theologiae y De potentia Dei. ${ }^{1}$ Hemos excluido la Summa Theologiae, "manual de teología" para estudiantes por excelencia. También excluimos el hermoso y profundo comentario Super Evangelium S. Ioannis, donde expone santo Tomás el concepto de relación trinitaria partiendo del texto evangélico. Hemos creído conveniente adentrarnos en escritos menos conocidos y estudiados. A partir de las obras elegidas trataremos de precisar lo que el Aquinate entiende por relaciones, es decir, las propiedades que distinguen a las personas y nos permiten discernir lo que es propio de cada uno en la Trinidad.

Partamos de una premisa metodológica: no podemos compartir la opinión que se inclina a pensar que lo realizado por el Aquinate es simplemente un excepcional trabajo de lógica aplicada a la teología. No es ni mucho menos la finalidad del Doctor, sino que trata, más bien, de dar respuesta a las "arenas movedizas" en las que se movía la reflexión de algunos teólogos de su momento o de poco tiempo antes. Así, por ejemplo, veremos cómo afirma que las relaciones son cuatro, de las cuales tres dicen oposición. Responde así a las diversas corrientes o maestros escolásticos que, o bien negaban la existencia de relaciones reales en Dios, o bien las multiplicaban hasta el infinito. Por ejemplo, Prepositino de Cremona (1150-1210) llegó a afirmar que cuando decimos que el Padre se diferencia del Hijo por la paternidad, viene a significar solo que el Padre es el padre. Como es obvio, esta forma de discurrir no es más que un modalismo larvado, en cuanto que si decimos paternidad, filiación o procesión, tan solo indicamos modos de hablar. Solo hay una esencia divina y personas ya diferenciadas, luego no hay ni relaciones ni nociones en Dios. Santo Tomás nos ayuda a entender que la paternidad y el

1 Los textos latinos que en este trabajo aparecen de los diversos escritos de Santo Tomás son tomados de Opera Omnia en <http://www.corpusthomisticum.org > [acceso: 28 de agosto de 2020]. Los textos y referencias de estos escritos en castellano son Comentario a las sentencias de Pedro Lombardo, vol. I/1: El misterio de la Trinidad (Colección de pensamiento medieval y renacentista 35), Pamplona, Eunsa, 2002; "Compendio de Teología", en Opúsculos y cuestiones selectas, vol. V, Madrid, BAC, 2008, 19-328; "Cuestiones disputadas sobre la Trinidad", en Opúsculos y cuestiones selectas, vol. III, Madrid, BAC, 2005, 623-810; Suma contra los gentiles, vol. II, Madrid, BAC, $2007^{2}$. 
Padre es lo mismo realmente, pero nuestra percepción nos obliga a hablar como "desdoblando" el ser de Dios. La síntesis del Angélico tiene, a mi parecer, dos puntales importantes. Uno es la metafísica de Aristóteles y su concepción de la relación como una de las categorías con las que puede ser expresada el"ser". Otra será el camino abierto por san Agustín en Occidente donde, en contraposición con las dos grandes corrientes heréticas - arrianismo y sabelianismo- cantará las bondades de las procesiones y las relaciones divinas, elementos insoslayables en el conocimiento de la vida intradivina. Aunque no están ausentes en la reflexión del Aquinate teólogos insignes como Boecio, Anselmo de Aosta, Pedro Abelardo, Ricardo de San Víctor, etc.

La división indica la dedicación de un epígrafe a cada una de las obras señaladas. En cada uno de ellos introducimos, a modo de"cuestiones introductorias", algunos aspectos importantes de la obra que nos ayudarán a conocer mejor lo que allí se afirma sobre la relación. En el Scriptum super Sententiis, primera gran obra de síntesis, vemos cómo la estructura del tratado viene dada por la propia obra del Lombardo, el comentario que realiza el Aquinate tiene como idea central que la procesión de las personas divinas en la unidad de la esencia es la causa de la procesión en las criaturas. En la Summa contra Gentiles constatamos cómo el tratado trinitario - Libro IV- se articula sobre las dos procesiones: generación del Hijo y procesión del Espíritu Santo. Es en esta obra donde aparece por primera vez, en la teología tomasiana, la doctrina delVerbo y del Amor, propia del Hiponate. Con respecto al Compendium Theologiae, podemos indicar que presenta la doctrina de la relación vinculada a la doctrina del Verbo y del Amor, que poco antes ha desarrollado. El De potentia Dei, fiel a la estructura de las cuestiones disputadas, es sin duda el más analítico y difícil de entender.Veremos cómo en esta obra aparece una doctrina muy desarrollada sobre las relaciones, como es lógico también sobre las procesiones y personas. El camino teológico recorrido por santo Tomás pasa por la profundización del concepto mismo de relación; profundización que tiene su punto de partida en la afirmación de la existencia de relaciones reales en Dios y cuyo punto de llegada no será otro que las propias personas divinas en cuanto que vienen definidas por las relaciones.

De la fuente de san Agustín bebe santo Tomás, para quien la fe católica exige el reconocimiento explícito de relaciones reales en Dios. Para demostrar la existencia de dichas relaciones reales no recurre tan solo a los argumentos de autoridad de la Tradición (especialmente el Hiponate) sino que busca razones de verdad. Estas razones se fundan en el análisis detallado de la"relación". Lo"relativo" es la cosa misma que se encuentra 
referida a otra realidad. Por su parte la "relación" es el accidente que, en la cosa relativa, consiste en la vinculación a otra cosa. Los"relativos" que estudia la teología trinitaria como Padre, Hijo y Verbo, Amor y Don son relativos "según el ser", es decir, que significan formalmente la relación en cuanto referencia a otro. Para santo Tomás, en Dios hay relaciones y esto es para todos los cristianos: "quod apud omnes Catholicos certum est relationes esse in divinis". ${ }^{2}$ La veritas fidei implica que la única distinción en Dios viene de las relaciones opuestas, pues en Dios, dada su plena simplicidad, solo puede haber esencia divina o relaciones opuestas. ${ }^{3}$ Es necesario para santo Tomás responder a la comprensión de la Unidad y Trinidad en Dios en respuesta a las antiguas herejías del arrianismo y del sabelianismo. ${ }^{4}$

La unidad y distinción de las personas aparece especialmente en las manifestaciones de la Trinidad. El Padre y el Hijo pueden ser diferenciados por nuestro intelecto gracias a las relaciones de paternidad y filiación que implican distinción según el "orden de origen", que indican distinción real de las diversas personas. Paternidad y filiación son relaciones reales ya que, bajo tal aspecto en orden a la naturaleza, orden por el que el Padre dona al Hijo todo lo que tiene, incluso el ser principio del Espíritu Santo. Todo lo dona excepto el ser padre, que es opuesto, en cuanto distinción formal, de ser hijo. Habla santo Tomás de eterna generación, orden"según la verdad". ${ }^{5}$

2 Scriptum super Sententiis I, d. 26, q. 2, a. 1.

3 "Respondeo dicendum, quod veritas fidei habet quod in divinis solum est distinctio quae est secundum relationes oppositas; relatio autem, sicut et quaelibet forma, habet esse ex comparatione ad illud cui inest": Quodlibet XII, q. 1, proem.

4 "Haec autem distinctio non potest esse secundum aliquod absolutum: quia quidquid absolute in divinis praedicatur, Dei essentiam significat; unde sequeretur quod personae divinae per essentiam distinguerentur, quod est haeresis Arii. Relinquitur ergo quod per sola relativa distinctio in divinis personis attenditur. Haec tamen distinctio non potest esse rationis tantum: quia ea quae sunt sola ratione distincta, nihil prohibet de se invicem praedicari, sicut dicimus principium esse finem, quia punctum unum secundum rem est principium et finis, licet ratione differat; et ita sequeretur quod pater est filius et filius pater, quia, cum nomina imponantur ad significandum rationes nominum, sequeretur quod personae in divinis non distinguerentur nisi secundum nomina: quod est haeresis Sabelliana": De potentia Dei., q. 8, a. 1.

5 "Haec autem oppositio non potest nisi ex hoc esse quod unus eorum refertur ad alterum. Nam diversae relationes duorum ad aliquod tertium, non directe sibi opponuntur, nisi forte ex consequenti per accidens. Unde relinquitur quod ad hoc quod distinguatur Spiritus sanctus a Filio, oportet attribui eis oppositas relationes, quibus ad invicem opponantur. Nec possunt aliae inveniri nisi relationes originis, secundum quod unus est ab alio". In Ioan., c.16, l. 4. 
En orden a la metodología usada diremos que en cada epígrafe trataremos ciertos temas introductorios y posteriormente analizaremos los textos que, a nuestro parecer, son esenciales para una correcta clarificación del tema que queremos desarrollar.

\section{LA RELACIÓN TRINITARIA EN EL SCRIPTUM SUPER LIBROS SENTENTIARUM}

Santo Tomás llega a París como bachiller sentenciario en 1252. Inicia su labor docente bajo la responsabilidad del Maestro Elías Brunet de Bergerac dedicándose a la actividad de comentador de las Sentencias de Pedro Lombardo. Fruto de dicha actividad académica surge el Scriptum super libros Sententiarum, cuya redacción completa viene datada en el 1257. Esta obra a pesar de ser ciertamente genial no representa el pensamiento definitivo de santo Tomás que llegará con obras como Summa contra Gentiles, las Quaestiones Disputatae o la propia Summa Theologiae. Podemos decir que, en Super Sent., el pensamiento especulativo del Aquinate no ha llegado al summum, a su plena capacidad.

\subsection{La estructura del Scriptum super libros Sententiarum: exitus-reditus}

En el proemio de Super Sent., santo Tomás proyecta el contenido de toda la obra partiendo de la Sagrada Escritura — exergo- basado en Sir 24,40 donde interpela la propia Sabiduría. Apunta el Aquinate que una certera definición de la sabiduría es aquella de san Pablo quien nos dice que "Christum Dei virtutem et Dei sapientiam, qui etiam nobis a Deo factus est sapientia" (1 Cor 1,24.30). La sabiduría indicada en el exergo viene a ser considerada el Hijo por modo de apropiación, es decir, apropiada por el Hijo - quodam speciali modo Filio - en cuanto que las obras de la sabiduría parece que convienen más a las propiedades de este. No se dice que el Padre no sea sabiduría, sino que Padre, Hijo y Espíritu Santo son una sabiduría como son una esencia. Son cuatro las apropiaciones que convienen sobremanera a las propiedades de dicha Sabiduría: la obra de la revelación trinitaria; la creación del universo; su restauración y su perfeccionamiento que debe entenderse como la conducción al fin. Las cuatro obras de la Sabiduría constituyen la estructura de los cuatro libros de Super Sent. Con esta cuádruple subdivisión, santo Tomás interpreta y ofrece el contenido de la obra de Las Sentencias de Pedro Lombardo. En nuestro estudio nos referiremos al primer libro el cual versa sobre la revelación de la vida trinitaria, esto es, de las 
procesiones eternas por las que el Hijo procede del Padre y el Espíritu del Padre y del Hijo.

La materia del Primer Libro de las Sentencias y del comentario de santo Tomás es la manifestación de la Trinidad mediante elVerbo Encarnado. Dios conoce perfecta y plenamente mediante su Sabiduría. Podemos leer: "ninguno conoce al Padre sino el Hijo y aquel a quien el Hijo se lo quiera revelar" (Mt 11,27) o"a Dios nadie lo ha visto, sino el Unigénito que está en el seno del Padre" (Jn 1,18). Es por esto por lo que en el exergo se dice en persona del Hijo: “Yo, la sabiduría, vertí los ríos". Estos ríos de los que nos habla la Escritura son para santo Tomás fluxus aeternae processionis, que se encontraban ocultos y, en cierto modo, confusos, sea en la semejanza de las criaturas o en los enigmas de la Escritura hasta que vino el Hijo de Dios y vertió los ríos encerrados haciendo que fuese público el nombre de la Trinidad. La divisio textus de I Super Sent. presenta la idea vehicular de todo este libro en cuanto que podemos hablar de exitus, una salida desde el principio que permanece inmanente a la misma esencia divina. La reflexión sobre la Trinidad parte de considerar que la salida de una persona de la otra, en la unidad de esencia, es la causa de la salida de las criaturas en la diversidad de esencia. Mediante lo indicado podemos decir que el Aquinate no antepone la Unidad de Dios a la Trinidad sino solo en aras de una mejor comprensión y clarificación; más bien articula estrechamente, incluso hasta entrelazar completa y constantemente, Unidad y Trinidad en Dios. Santo Tomás habla sin más dilaciones de "Trinidad de las personas en la unidad de esencia", ${ }^{6}$ conexión clara de Unidad y Trinidad en Dios. Para una mejor comprensión de nuestro objeto de estudio, tendremos que acercarnos al texto programático de I Super Sent., d. 2, q. 1. Podemos ver cómo santo Tomás parte de la unidad de la esencia divina preguntándose si Dios es solamente uno (art.1), hace suyo el pensamiento de Dionisio el Areopagita —De divinibus nominibus, 15por el cual afirmamos que la multitud de la totalidad viene reconducida a un primer principio de los entes que es Dios (oportet universitatis multitudinem ad unum principium entium primum reduci, quod est Deus). Esencia y existencia es lo mismo en Dios y esto implica que es imposible que la divinidad se multiplique y divida, hay un solo Dios. Dando por demostrada la unicidad, comienza santo Tomás el estudio de la pluralidad en Dios. En el art. 2 se cuestiona si se puede afirmar la existencia de varios atributos en Dios. Responde al respecto que lo que existe de perfección en lo creado viene del creador. Las perfecciones de los seres creados como sabiduría o bondad se encuentran en Dios de modo perfecto, pues en Dios se

6 Super Sent. I, d. 2, q. 1, a. 5. 
identifican la única esencia divina con dichas perfecciones a causa de su infinita simplicidad. Esta idea viene más profundamente desarrollada en la solutio del art. 3. Efectivamente, en la explicación de si la pluralidad de las nociones en Dios — según los cuales se diferencian los atributos- se encuentra solo en el intelecto o también en Dios. Explica en qué consiste dicha diferenciación y en qué modo los atributos son ex proprietate rei, y para tal fin propone un itinerario en cuatro etapas: aclarar en qué consiste la ratio; en qué sentido la ratio se encuentra en una cosa; si las rationes de los diversos atributos se encuentran en Dios o no; y finalmente si la pluralidad de las rationes se encuentra solo en nuestro intelecto o aliquo modo se encuentra ex parte rei.

Podemos decir que nuestro autor trata de dar respuesta al dilema con el que se habían encontrado los teólogos desde la Antigüedad, a saber: cómo poder hablar al mismo tiempo de unidad y de pluralidad en Dios sin menoscabar la unidad de esencia ni la trinidad de personas. El itinerario marcado lleva irremediablemente a afirmar que lo que es uno en Dios viene multiplicado en el intelecto humano pues no puede captar con un solo concepto los diversos modos de perfección de Dios. El alma humana no puede tener una visión de la esencia divina y debe comprender a Dios mediante una pluralidad de conceptos para representar la única realidad divina. Pero esto no significa que las rationes se encuentren tan solo en el intelecto humano, puesto que a la pluralidad de las nociones corresponde algo en la realidad que es Dios. Al respecto es interesantísima la respuesta que ofrece santo Tomás a la dificultad sexta del art. 3 donde nos dice que"en Dios todo es una misma cosa excepto la ingeneración, la generación y la procesión, que constituyen personas realmente distintas; pero no es necesario que todo aquello que se dice de Dios además de estas cosas sea una única realidad según la razón" ${ }^{7}$ De este modo son distinta re entre ellas, los atributos se diferencian ratione, a pesar de identificarse re con la esencia. Pero aún más nos dice el Aquinate - tomando el pensamiento de Boecio- que solo la relación multiplica la Trinidad, entendiéndose como una pluralidad real. Efectivamente nuestro autor hace suya esta reflexión central de la heredad boeciana en cuanto que la relación se considera punto de convergencia de la Unidad y Trinidad en Dios. Al respecto nos ha dicho en el mismo artículo que se debe distinguir entre las relaciones personales y los atributos esenciales y ambas nociones no se encuentran solo en el intelecto. Dios verdaderamente es Padre como es verdaderamente sabio, aunque ambas nociones son diversas entre sí. A la base de lo dicho se encuentra la afirmación de

7 Super Sent. I, d. 2, q. 1, a. 3. 
que en Dios solo se encuentran dos predicamentos como son la esencia divina y la relación. Sabiduría, bondad o poder hacen referencia a la esencia mientras que paternidad, filiación y procesión son relaciones. En cuanto a esta noción -incide el Aquinate - debe tenerse en cuenta que podemos hablar de una doble comparación, a saber, una con respecto a su correlativo, por la que se relaciona con alguna otra realidad, y la otra con respecto a la esencia, identificándose realmente con ella, es decir, que la esencia en Dios se identifica con la propia relación. Hemos ya expresado que la multiplicidad en Dios, es decir, la pluralidad de personas en la unidad de esencia divina pertenece al dominio de la veritas fidei (art. 4), pero a la vez debemos decir que la esencia divina y las personas se identifican (essentia et suppositum sunt in Deo idem re), aunque difieren según ratio. En el art. 5 se nos propone una cuestión bastante interesante para nuestro planteamiento como es la real diferenciación de las personas divinas. Se afirma que las personas se distinguen realmente entre ellas y no solo según ratione, esto se debe a que la real diferenciación de las personas es consecuencia de la existencia de dichas relaciones. La razón de relación se entiende como"referencia al otro"y se puede establecer una doble comparación en cuanto que puede considerarse tanto con la propia esencia - a modo de cualquier otro atributo o término esencial (idem re, differunt ratione) — o puede venir comparado con el relativo en virtud de la propia razón de relación, existiendo entre ambos términos relacionales una distinción in re. Es de vital importancia para la salvaguarda de la fe revelada que las personas se distingan realmente y no solo ratione. Las personas divinas se distinguen realmente porque la comparación de la relación viene referida al propio correlativo y no a la esencia. La no distinción real de las personas lleva directamente, según santo Tomás, al sabelianismo. ${ }^{8}$

En este primer acercamiento, en la $d .2$, hemos tratado de presentar el papel central que juega la relación en la articulación de la Unidad

8 Como aparece en la $d$. 26, es argumento de fe la existencia de relaciones reales en Dios: "Apud omnes catholicos certum est relationes esse in divinis". Es importante esta afirmación porque señala santo Tomás los dos grandes errores teológicos existentes al respecto de la relación divina como son los de Sabelio y el Porretano. Al primer error, tan conocido por nosotros, se llega fácilmente si no afirmamos la existencia de relaciones reales en Dios. A las relaciones divinas se les atribuye - como hemos visto desde Boecio- la tarea de distinguir realmente las personas de la Trinidad salvaguardando la unidad de esencia divina. De otro lado la herejía del Porretano consiste en la doctrina llamada de las "relaciones asistentes", la cual niega en Dios la identidad de esencia y relación. Cf. GiovanniVentimiglia, "Le relazioni divine secondo S. Tommaso d'Aquino. Riproposizione di un problema e prospettive di indagine", Rivista di filosofia neoscolastica 82 (1990) 287-299. 
y Trinidad divinas. Para ello nos hemos valido de la distinción res/ratio como instrumento usado por santo Tomás en aras de una mejor comprensión. Pero hemos de retener como claro que esta distinción res/ratio adquiere dos modulaciones distintas según se use para los atributos esenciales o para la relación divina en cuanto punto de partida en la diferenciación real de las personas divinas. Con respecto a lo que atañe al ligamen entre las relaciones y la esencia divina, la distinción re/ratione nos ayuda a diferenciar los"varios" en la Unidad divina. Así, por ejemplo, la relación de paternidad no difiere de la esencia divina según re, sino que ambas se identifican; también en comparación con la filiación constituye la razón formal de la distinta realidad de las dos personas divinas.

\subsection{Análisis de la relación trinitaria en el Scriptum super libros Sententiarum}

Llegados a este punto cabe realizar un breve repaso sobre lo que santo Tomás entiende por la relación en Dios para introducirnos posteriormente en el estudio de la distinctio 26, que se nos antoja clave en el comentario a la obra del Lombardo. Santo Tomás - tomando la autoridad de Boecio - afirma que el nombre de Trinidad pertenece a la relación y no a la esencia divina. Se introduce la pluralidad en Dios debido a las relaciones en cuanto que subsisten en la esencia divina. Cuando decimos Trinidad decimos un solo Dios, pero al mismo tiempo que Dios es trino, con otras palabras: cuando decimos Trinidad decimos al mismo tiempo unidad de esencia y distinción real de personas. ${ }^{9}$ La autoridad de Agustín afirma que todo lo que se puede decir de Dios o se dice según la substancia o según la relación, no cabe otro predicamento. Pero ¿acaso no es la relación un accidente? ¿cómo, entonces, puede aplicarse a Dios? Contesta el Aquinate a dicha cuestión diciendo que la relación conviene a la simplicidad divina, puesto que al ser su ratio "pura referencia a otra cosa", puede ser aplicada directamente a Dios, ya que está vacía de cualquier tipo de contenido. No añade nada a la substancia pues de suyo no se inhiere en ella. La relación ocupa un lugar único, puesto que su ratio no va en consonancia con el resto de accidentes - no toma como referencia un sujeto al cual inherirse-, sino que atañe a una referencia a alguna otra cosa. Es este el"privilegio" por el que puede aplicarse a Dios; al no añadir nada a la substancia no contradice la infinita simplicidad de la esencia divina. ${ }^{10}$ Todos los géneros de accidente comportan una

\footnotetext{
9 Cf. Super Sent. I, d. 24, q. 1, a. 2.

10 Cf. Super Sent. I, d. 8, q. 4, a. 3.
} 
imperfección, por ejemplo, la cantidad o la cualidad implican disposición en una substancia; no pueden aplicarse a Dios. ${ }^{11}$ Efectivamente la razón formal propia de la relación no se toma de su referencia al sujeto en que está, sino por referencia a algo que se encuentra fuera de él (ad aliquid extra).

Una vez que hemos tratado de enmarcar la relación intratrinitaria en la articulación de la Unidad y Trinidad en Dios salvaguardando la ortodoxa fe católica analizaremos la relación en el marco de las propiedades personales tal como aparece en la distinctio 26. El punto de partida es la hipóstasis en la divinidad, efectivamente, en la articulación tomasiana solo puede hablarse de la distinción en la divinidad si a la base existen "verdaderas" hipóstasis en Dios. Tenemos que recordar que la hipóstasis señala el individuo de la substancia (individuum substantiae), lo que se conoce como substancia primera, es decir, aquello que es distinto, subsistente e incomunicable. Por lo que santo Tomás afirma que la hipóstasis divina es "aquello que es per se subsistente, distinto e incomunicable" (hypostasis divina erit illud quod est per se subsistens, distinctum et incommunicabile) ${ }^{12}$ La hipóstasis en Dios, como en las demás hipóstasis, es lo que hace "distinto" al individuo. En el ser humano, podemos decir que la materia individualiza al"humano concreto", pero ¿y en Dios? Nos es conocido que no cabe ningún tipo de accidente en la divinidad, por lo que solo tenemos esencia y relación. La esencia divina no puede distinguir, en cuanto que es propiamente lo común en los Tres. Solo cabe la distinción en lo relativo y la hipóstasis está íntimamente unida a la relación. Pero no cabe olvidar que según re, la relación es lo mismo que la esencia, así la distinción es según ratione. La hipóstasis se identifica según re con la esencia y en Dios es considerada como"la distinta relación en cuanto subsistente en la naturaleza divina". ${ }^{13}$ Nos encontramos con un aspecto importante de la hipóstasis debido a que su definición no coincide del todo con la de persona. Santo Tomás, como es sabido, toma la definición boeciana ya en esta obra: "substancia individual de naturaleza racional", ${ }^{14}$ pero no desecha otras definiciones como aquella de Ricardo de San Víctor ${ }^{15}$ y una tercera conocida como "la de los

11 Especialmente clarificadoras encontramos estas palabras del Aquinate en Super Sent. I, d. $8, q .4, a .3$.

12 Super Sent. I, d. 26, q. 1, a. 1.

13 "Hypostasis in divinis significat relationem ut distinctam per modum subsistentis in natura divina": ibid.

14 Véase al respecto Super Sent. I, d. 25, q. 1, a. 1.

15 Ricardo de San Víctor define la persona como "divinae naturae incommunicabilis existentia", el de San Víctor expresa una definición concerniente solo a la persona divina mientras que aquella de Boecio tiene un componente más general. La primera trata 
maestros": "la persona es una hipóstasis distinta con una propiedad que pertenece a lo perfecto (hypostasis distincta proprietate ad nobilitatem pertinente)". Tomando esta definición, santo Tomás viene a decir que la persona incluye de por sí la razón de "dignidad" como razón especial de distinción en la medida que expresa algo subsistente en una naturaleza noble como es la naturaleza intelectual. ${ }^{16}$ La especial definición que ofrece santo Tomás de la hipóstasis divina como la "relación en cuanto subsistente en la naturaleza divina" hace imposible desechar — mediante el intelecto- la relación intratrinitaria si se quiere conservar la alteridad real de las hipóstasis divinas. Dicho de otra forma: si se quita, o no se entiende bien, la relación en Dios - lectura sabeliana o del Porretanono hay forma de distinguir realmente la pluralidad divina en la unidad de esencia. No hay pues diferenciación en las personas divinas, es más, si se abstrae la relación no permanece nada: ni absoluto, ni relacionado, ni hipóstasis, ni esencia. ${ }^{17}$

Santo Tomás entiende la relación en el marco aristotélico del propio concepto, son dos los términos en correlación. Señala al respecto una diferencia clave para poder entender las relaciones en Dios como son las relaciones "reales" (habent fundamentum in re) y "de razón" (relationes rationis). Las primeras tienen algo en la realidad sobre las que se funda su ser (habent aliquid in re) — como es el caso de la igualdad, que se funda sobre la cantidad-, estas son realmente algo en la realidad. Las segundas, sin embargo, no tienen fundamento en la realidad de la que se predican — como derecha e izquierda. Esta división es muy importante en lo que respecta a la Trinidad en cuanto que solo las relaciones reales distinguen las personas divinas, ya que las relaciones son el único principio de relación en Dios. Llegamos a una máxima en el pensamiento del Aquinate, ya que las relaciones de paternidad y filiación no solo son reales (habent fundamentum in re) —algo ya propio del logos católico-, sino que debido a la suma simplicidad divina son idénticas a las personas en las que están las relaciones. ${ }^{18} \mathrm{Si}$ en Dios solo hubiese relaciones de razón caeríamos en la herejía sabeliana y no se distinguirían las distintas hipóstasis. La relación implica distinción en Dios, puesto que ofrece "oposición relativa". La virtualidad que ofrece la relación es que en las cosas relativas no existe oposición en cuanto que la relación esté en algo, sino en cuanto que es respectivo a otra cosa. Solo la oposición

\footnotetext{
de corregir a la segunda, en cuanto que encuentra que los términos"racional", "indi-

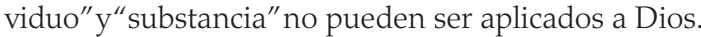

16 Cf. Super Sent. I, d. 26, q. 2, a. 1.

17 Véase al respecto Super Sent. I, d. 26, q. 2, a. 2.

18 Cf. Super Sent. I, d. 26, q. 2, a. 1.
} 
de relación puede introducir distinción en las personas al no introducir una comparación entre algo perfecto y algo imperfecto como puede ser el caso de otros tipos de oposición, como lo perfecto o imperfecto. Pedro Lombardo expresa en su escrito - tomando como base lo expresado por el Hiponate en el De Trinitate VI - la regla general por la que hay cosas que pueden decirse de modo absoluto y cosas que se dicen de modo relativo. Esto mismo viene aplicado a Dios en cuanto que de modo absoluto se atribuye a las distintas personas a la vez: hacemos referencia a lo que se dice de la substancia divina. Pero en cuanto el modo relativo nos afirma que en Dios solo puede hablarse de diferenciación real en la oposición de relación puesto que nos da a entender que solo hay tres res si existe tal oposición. Importante afirmación esta, ya que, aunque hablamos de cinco nociones en Dios —innascibilidad, paternidad, filiación, espiración común y procesión-, solo son tres "realidades": Padre, Hijo y Espíritu Santo. Estas tres realidades solo se diferencian por la oposición de relación, de esta manera, el Padre se diferencia del Hijo, por la paternidad y por la filiación. Pero la paternidad o la filiación no expresan oposición con la espiración común, por lo que no podemos decir que haya dos realidades —si hablamos de paternidad-espiración común o filiación-espiración común- sino una sola res y dos relaciones, comprendidas estas como dos "nociones" por las que se entiende el Padre. ${ }^{19}$ La existencia de tres res en Dios que vienen determinadas por la oposición de relación implica que no son varias las propiedades que convienen a cada una de las personas, sino a cada persona le corresponde una propiedad, entendida esta stricto sensu, siempre teniendo en cuenta que al Padre también le corresponde la innascibilidad. Podemos decir que la res "Padre" puede venir expresada por tres nombres: Padre, paternidad y generación. Las tres expresan una misma realidad y solo se diferencian según razón, es decir, difiere el modo de significar. Padre expresa dicha res a modo de persona, paternidad a modo de propiedad y generación a modo de operación personal. ${ }^{20}$ Mas también añade el Aquinate que la relación (propiedad) en cuanto constituye y distingue a la persona es anterior a tal persona e incluso anterior al concepto de operación personal. Por lo que la paternidad es anterior - no en cuanto res sino en cuanto modo de significar - a Padre y a la propia generación. Tal aseveración solo tiene razón de ser si se comprende la relación como constitutiva de la propia persona divina, es más, considerándola como la propia persona

19 Véase Super Sent. I, d. 27, q. 1, a. 1.

20 Véase Super Sent. I, d. 27, q. 1, a. 1, ad. 5. Es interesante constatar cómo el Angélico no utiliza la doctrina delVerbo y del Amor. Esta vendrá desarrollada a partir de la Summa contra gentiles. 
subsistente. ${ }^{21}$ Ha indicado el Aquinate la "anterioridad" de las relaciones con respecto a las personas en correlación a lo afirmado en el d. 26, q. 2, a. 2 donde afirma que las hipóstasis no permanecen si son quitadas las relaciones mediante el entendimiento. Las relaciones son las personas divinas, pero aún más: son la propia esencia divina. Así de contundente lo afirma el Angélico ${ }^{22}$ y para ello tiene que basarse, como no podía ser menos, en la consideración de la existencia de relaciones reales en Dios. El desarrollo teológico parte de que las relaciones en Dios, en cuanto reales, están fundadas sobre algo verdaderamente existente como es la comunicación de la naturaleza. Pero en la absoluta simplicidad divina no cabe distinción entre esse, quod est y quo est. De manera que la paternidad no puede ser otra cosa que la esencia divina. Según re la paternidad no puede formar un compuesto con la esencia, sino que ambas son la misma cosa. La diferenciación solo concierne al concepto. ${ }^{23}$ Un apunte importante que debemos de tener en cuenta es que si bien las relaciones, según realidad, son la esencia, no podemos decir que las relaciones entre ellas sean la misma cosa también según la realidad, puesto que es precisamente la distinción real por la oposición de relación lo que permite la multitud real en Dios. La perfecta sistematización de esta idea vendrá con la Summa Theologiae.Vemos, pues, cómo, encorsetado por los moldes que le brinda la estructura de la obra del Lombardo, el Aquinate expresa la importancia de las relaciones, en cuanto que solo desde estas pueden distinguirse las personas en la única esencia divina.

\section{LA RELACIÓN EN LA SUMMA CONTRA GENTILES}

A continuación, vamos a abordar la cuestión de la relación trinitaria en la Summa contra Gentiles tratando de subrayar la novedad metodológica que presenta dicho texto con respecto a otros de corte más escolástico, como puede ser el De Potentia Dei, o la propia Summa Theologiae. Nos encontramos ante la obra que, según los especialistas, mayores problemas presenta cuando se quiere determinar la intención del autor, el método teológico seguido, la fecha de su composición o sus destinatarios. Un

21 Véase Super Sent. I, d. 27, q. 1, a. 2. El ejercicio de profundización realizado por el Aquinate busca la clarificación y el asiento de la importancia de los diversos conceptos en uso. La relación no puede ser considerada, en Dios, como asistente o extrínseca - como la entiende el Porretano-, sino que constituye a la propia persona divina siendo también la misma persona divina.

22 "Simpliciter confitendum est proprietates esse divinam essentiam": Super Sent. I, $d$. 33, a. 1.

23 Cf. ibidem. 
estudio de todos estos elementos no es por supuesto el objetivo de nuestro estudio, pero se nos hace necesario fijarnos especialmente en dos de estos como son la intención y el método seguido por el Aquinate.

\subsection{Elementos introductorios de la Summa contra Gentiles}

Podemos afirmar con respecto a la datación de la obra, con esto nos bastará, aunque no es todavía posible fijar con precisión y certeza absoluta el lugar y la fecha de composición, que la Summa contra Gentiles - en adelante, SCG - terminó de ser redactada en 1264. La SCG es sin duda una obra de teología — diremos de "teología pura" — como puede ser la propia Summa Theologiae, aunque si tomamos la definición de summa de Roberto de Melún como "singolorum compendiosa collectio", deberíamos decir que propiamente la SCG no es una summa porque no es una ni suma ni sumario ni resumen. Ciertamente esta obra tiene como finalidad instruir al creyente dándole a conocer la verdad de la fe católica que profesa, haciéndole ver que nuestra fe es verdadera. La intención del Aquinate en la obra es responder a la cuestión" an sit verum id quod fides catholica credit". A poco que nos acerquemos a sus páginas constatamos cómo son sometidos a duro examen toda suerte de paganos, musulmanes, hebreos, herejes. Encontramos trazas de una teología apologética, no en vano dio en llamarse esta obra" Liber de veritate catholicae fidei contra errores infidelium" ${ }^{24}$ Gran interés tiene para nuestro estudio el método teológico que presenta la obra, puesto que nos ayudará a obtener claves de lectura y comprensión del discurso sobre la Trinidad en general y de la relación en particular. En SCG I, 1 podemos leer cómo el Aquinate acepta el papel de "sabio" como"buscador de la verdad", más aún, "buscador de laVerdad suprema", pues se presenta como quien "considera las causas más altas", quien considera las causas supremas. La Verdad que permanece detrás de cada verdad: sabio era Aristóteles, pues era"buscador de las causas supremas". Pero se puede considerar aún más sabio quien busca la Verdad como la más suprema de las causas. El trabajo del sabio buscador de laVerdad es doble: exponer laVerdad divina como verdad por antonomasia e impugnar el error contrario a la Verdad, que no es solo un error de tipo gnoseológico, sino que es verdadera impiedad puesto que lo contrario a la Verdad no es la falacia sino la mencionada

24 No podemos olvidar el empeño de santo Tomás en la controversia con los cristianos cismáticos de oriente por lo que se hacía necesaria una clarificación doctrinal en lo que corresponde al pensamiento sobre la Trinidad y la Encarnación. Cf. Marie Dominique CHenu, Introduzione allo studio di S. Tommaso d'Aquino, Firenze, Libreria Editrice Fiorentina, 1953, 252-253. 
impiedad. ${ }^{25}$ Teniendo en cuenta lo dicho encontramos más sentido en la comprensión de aquello que se nos dice en SCG I, 2 a modo de "texto programático": "Nos proponemos manifestar, en cuanto nos sea posible, la verdad que profesa la fe católica, eliminando los errores contrarios". Es imposible, pues, expresar la verdadera fe católica sin eliminar los errores contrarios. Queda configurada la metodología seguida: exponer impugnando con la finalidad de que la Verdad aparezca más resplandeciente. Santo Tomás presenta, para después impugnar, los errores contrarios a la verdad católica, pues la aceptación de una verdad lleva pareja el rechazo del error que le es contrario. ${ }^{26}$ En el plano de la obra — que se divide en cuatro libros - se encuentra como elemento vehicular un doble orden de verdades: de un lado encontramos verdades de Dios que sobrepasan toda razón, como que Dios es Uno y Trino, otras sin embargo, son alcanzadas por la propia razón humana. ${ }^{27}$ Hubo filósofos que hablaron de la unidad de Dios, que es creador, causa primera de todo lo existente. Filósofos guiados por la luz natural de la razón. ${ }^{28}$ La doble condición de verdad en Dios funda una doble aplicación de la sabiduría ya que hace referencia a la"sabiduría filosófica" y la"sabiduría teológica". La primera introduce a la segunda, y es así como lo presenta el Aquinate a lo largo de su obra; así, los tres primeros libros (Dios, la creación y la vida moral) tienen como objeto verdades accesibles a la razón. No podemos olvidar por un momento que la SCG es un libro de teología, todo entero. No debe decirse que los tres primeros libros constituyen, por así decirlo, una suma filosófica, reservando la categoría de teológica solo al Libro IV. Las verdades de razón se presentan como pertenecientes de pleno derecho al depósito de la fe y como tales deben ser demostradas y defendidas. ${ }^{29}$

25 Cf. SCG I, 1.

26 Cf. Quintín Turiel García, "La intención de Santo Tomás en la Summa contra Gentiles”, Studium. Revista de Filosofía y Teología 14 (1974) 395. Al respecto nos dice el propio Aquinate: "Eiusdem autem est unum contrariorum prosequi et aliud refutare sicut medicina, quae sanitatem operatur, aegritudinem excludit. Unde sicut sapientis est veritatem praecipue de primo principio meditari et aliis disserere, ita eius est falsitatem contrariam impugnare": SCG I, 1.

$27 \quad$ Especialmente clarificadora se presenta la lectura de los primeros capítulos del Libro I. En el c. 3 podemos percatarnos de la doble condición de verdad en Dios; en el c. 5 se nos dice que el conocimiento de las "verdades no demostrables" y su revelación son del todo necesarias para el hombre; en el c. 6, que asentir a ellas no puede ser tildado de ligereza; en el c. 7 que la verdad de la fe cristiana no puede estar en oposición con las verdades de la razón natural; en el c. 8 que dichas verdades de fe no pueden ser demostradas; en el c. 9 se nos dice el orden y modo con el que va a proceder en la obra teniendo en cuenta dichas verdades.

28 Cf. SCG I, 3.

29 Cf. CHenu, Introduzione allo studio di S. Tommaso d'Aquino, 254. 
Más problemas plantean las verdades de fe, aquellas que no pueden ser demostradas sino simplemente creídas, inaccesibles por la razón, pero que no por ello son irracionales. En el SCG I, 9 nos muestra el Aquinate el proceder ante el doble tipo de verdad en Dios: ante aquellas verdades accesibles a la razón natural se ha de proceder per rationes demonstrativas; ante las verdades inaccesibles a la razón natural no cabe demostración alguna, no cabe convencer al adversario con el apoyo en argumentos de razón, los únicos argumentos válidos y eficaces son los de la autoridad de la Escritura. ${ }^{30}$ Repetimos diciendo que las verdades de fe inaccesibles a la razón no pueden ser demostradas, pero sí se puede responder a las razones que el adversario aduzca contra ellas. Así vemos cómo el método seguido determina el orden de la obra y el modo con el que procede: primero trata sobre las verdades de fe accesibles a la razón, dando pie a la primera parte de la obra, que consta de los tres primeros libros. En un segundo momento trata sobre las verdades inaccesibles a la razón y lo hace respondiendo a las objeciones que los adversarios esgrimen en contra y declarando la verdad de la fe mediante argumentos de autoridad, es el modo de proceder en el Libro IV. ${ }^{31}$ Hemos tratado de presentar ciertos trazos de la metodología desarrollada por el Aquinate en la obra que traemos entre manos, teniendo en cuenta tal metodología, ¿cómo poder acercarnos al misterio inefable de la Trinidad? Dicho de otra manera, ¿cómo conocer al Dios que es Uno y Trino a la vez? El conocimiento del Dios Trino es tan imposible como imposible es conocer la esencia divina en sí misma. Entonces, ¿solo podremos conocer de Dios desde las huellas dejadas en la creación? ¿Conocer solo aquello que los filósofos perfilaron, que es uno, eterno, todopoderoso, absolutamente simple e inmaterial, vértice supremo de la perfección, causa primera de lo existente? De gran profundidad es lo expresado por el propio Aquinate en el prólogo del Libro IV. El camino gnoseológico de conocer a Dios desde las huellas de la creación se presenta inadecuado e insuficiente, ya que la unidad de la operación divina ad extra nos hace imposible ver huellas de la Trinidad en la propia creación. En el Salmo 27 podemos leer cómo es propio del hombre y en especial del creyente la búsqueda del rostro de Dios, un rostro que es Trino. Por ello propone el santo la existencia de verdades, como es la Trinidad, que sobrepasan toda razón y se presentan para que sean creídas y no entendidas, ya que sobrepasan toda experiencia sensible que constituye, según la gnoseología tomasiana, la única fuente del conocimiento. Puede parecer una contradicción que para

\footnotetext{
30 Cf. SCG I, 9.

31 Cf. Turiel García, “La intención de Santo Tomás en la Summa contra Gentiles”, 398-399.
} 
tener un conocimiento más cierto de Dios sea necesario acoger desde la fe aquello que sobrepasa de lleno la capacidad racional del hombre y por ello no puede ser objeto de demostración, esto no presupone que lo revelado sea contrario a la razón. Dios no puede ser nunca a-lógico y también cualquier conocimiento cierto de Dios proviene de Dios mismo que ha querido mostrarse, bien por revelación o bien por ser vértice de toda perfección. ${ }^{32}$ La revelación del Dios Trino como tal revelación se vierte en moldes a la medida del entendimiento humano, en conformidad con la naturaleza del hombre. Dicho entendimiento es susceptible de orden y perfeccionamiento, por lo que la revelación de las verdades de fe guarda cierto orden y camina por la senda de la perfección — esto no quiere decir que la perfección sea "imperfecta" en sí, sino que es "captada" por el hombre imperfectamente- pues no olvidemos que todo conocimiento en el hombre parte de los sentidos. Cuando el entendimiento humano se vea libre de tal dependencia por la sublimación de la "luz de la gloria", nos encontraremos ante el tercer y más elevado modo de conocimiento de lo divino, modo"angelical", no basado en los sentidos, sino que parte de poder ver a Dios"cara a cara", consiste en poder ver el rostro Trino del Dios único, pues ahora lo vemos per speculum et in aenigmate. ${ }^{33}$

Como anteriormente hemos indicado solo podemos conocer la Trinidad por el camino revelado, no podemos seguir el camino gnoseológico criatura-creador buscando huellas del Dios que es Trinidad. El punto firme sobre el que se basa nuestro autor es la Escritura. Bien sabe que los errores de Arrio, Sabelio, Fotino o Eunomio no dejan de ser una lectura insuficiente de la Sagrada Escritura. El principio de cualquier herejía es una interpretación parcial de las verdades reveladas en la Biblia debido a una exégesis errónea. El genio del Aquinate consiste en mostrar la plena compatibilidad de dichas verdades reveladas con la razón natural. No es aborrecida por la mente humana en su razón la generación del Hijo por parte del Padre, la procesión del Espíritu Santo por parte de Padre e Hijo, o la misma Trinidad de personas en Dios. Que dichas verdades no sean demostrables por la razón no quiere decir que sean irracionales. ${ }^{34}$

¿Cómo viene presentada la cuestión trinitaria en la SCG? A estas alturas ya sabemos que se sitúa en el cuarto libro, más concretamente en los capítulos 2-26. Tras una lectura atenta de los textos llama poderosamente la atención cómo esta parte viene estructurada sobre las dos

32 Cf. Riccardo FerRI, Il Dio Unitrino nel pensiero di Tommaso d'Aquino dal Commento alle Sentenze al Compendio di teologia (Contributi di teología), Roma, Città Nuova, 2010, 120-121.

33 Cf. SCG IV, 1.

34 Cf. FerRI, Il Dio Unitrino nel pensiero di Tommaso d'Aquino, 123-124. 
procesiones reveladas en la Escritura: generación del Hijo (cc. 2-14) y procesión del Espíritu Santo (cc. 15-25). El c. 26 explica la inexistencia de más procesiones inmanentes en Dios que las dos indicadas. En cada una de las partes mencionadas viene determinado el fundamento escriturístico de la generación y de la procesión; la refutación de las herejías que atentan contra dichas verdades reveladas. El examen de estas se constituye como instrumento privilegiado para adquirir la apropiada intelligentia fidei. Por último, afronta las objeciones racionales contra la fe en el Hijo y en el Espíritu Santo. ${ }^{35}$

En la SCG no podemos establecer una división - como durante tantos años se ha hecho- entre un De Deo Uno y un De Deo Trino. Como podemos constatar, la división establecida en el texto, a la luz de lo expresado por el propio Aquinate, es ciertamente gnoseológica y no ontológica, ya que atañe a nuestro conocimiento de Dios. El Libro IV de la SCG no viene configurado como un tratado sobre la Trinidad de Dios dejando al margen la única esencia divina, no es este el esquema tomasiano, sino, más bien, un ligamen entre la reflexión teológica en lo que trata sobre la Unidad y Trinidad. La doctrina trinitaria rige la dinámica de exitus-reditus que domina todo el planteamiento de la SCG. Dios es en sí fundamento de todo el actuar ad extra, aunque dicho actuar no determina el"ser trinitario" de Dios. ${ }^{36}$ Dicho con otras palabras: la creación no implica la Trinidad ni cómo es la Trinidad en su vida íntima. Aunque la $S C G$, en lo que se refiere al discurso trinitario, gira en torno a las dos procesiones inmanentes en Dios, solo desde el conocimiento de lo espiritual y por tanto del propio Espíritu podemos conocer de alguna manera la naturaleza de Dios. Es el propio Espíritu el que nos posibilita el asomo a la vida intradivina. Como es obvio, el conocimiento basado en la experiencia sensible no permite la demostración de las procesiones divinas. Solo desde el dato revelado podemos hablar de las dos procesiones divinas que son inmanentes, incorruptibles, inmutables, eternas y que no existen por emanación material sino espiritual. Dos procesiones inmanentes en una sola esencia divina, una misma esencia para la paternidad

35 Con respecto a la generación aparecen desarrolladas las siguientes cuestiones: fundamento escriturístico que afirma la existencia de la generación del Hijo por parte del Padre (cc. 2-3); la refutación de las herejías que atentan contra tal generación (cc. 4-9); las razones contra la generación delVerbo y soluciones contra dichas objeciones propuestas (cc. 10-14). Con respecto a la procesión del Espíritu Santo observamos un esquema similar: fundamento escriturístico de dicha procesión (c. 15); refutación de herejías que atentan contra la procesión del Espíritu Santo (cc. 16-18); razones y objeciones contra dicha procesión y consideración de estas (cc. 19-23). Encontramos dos capítulos dedicados a la importantísima cuestión del Filioque (cc. 24-25).

36 Cf. Ferri, Il Dio Unitrino nel pensiero di Tommaso d'Aquino, 138. 
y la filiación. Tendremos que señalar una idea central que propone el Aquinate con respecto a la diversidad en Dios, central para la distinción de las personas divinas, en especial para la distinción de Padre e Hijo: "Dios Padre es la esencia divina; Dios Hijo es la esencia divina, pero lo propio del Padre es que se distinga del Hijo por la paternidad por más que sean uno en razón de su divina esencia". ${ }^{37}$

\subsection{Análisis de la relación trinitaria en la $S C G$}

Santo Tomás no deduce la pluralidad en Dios, la Trinidad de personas, a partir del principio metafísico de la emanación, sino que se atiene a la revelación que nos habla de la generación divina por la que existe distinción en Dios, que ciertamente no es material ni de esencia. ¿Cómo presenta pues esta distinción el Aquinate de la vida intradivina? Entra en juego aquí la indispensable categoría de la relación intratrinitaria. Así el tratado trinitario en la SCG que gira en torno a las procesiones divinas inmanentes se completa con el estudio de las cuatro relaciones que vienen fundadas por dichas procesiones inmanentes. Dicho estudio, se nos antoja escueto pero central, viene señalado especialmente en el c. 14 de este cuarto libro que lleva por título"Solución de las razones invocadas contra la generación divina". No encontramos un trabajo de sistematización al modo de la Summa Theologiae o un mayor desarrollo en referencia a los contenidos como por ejemplo en De potentia, y esto es así porque simplemente no es el objetivo de la obra.

Entremos de lleno en el análisis de los textos que hacen referencia a las relaciones en la vida intratrinitaria; como es lógico, ciñéndonos a los primeros 26 capítulos del cuarto libro. $\mathrm{Al}$ respecto debemos decir que solo cuatro capítulos mencionan dichas relaciones, a saber: el c. 10, que lleva por título "razones contra la generación y procesión divinas"; el c. 14: "solución de las razones invocadas contra la generación divina"; el c. 24: "el Espíritu Santo procede del Hijo"; y por último el c. 26: "en Dios no hay más que tres personas: Padre, Hijo y Espíritu Santo". La relación intratrinitaria es entendida en el marco del discurso de las procesiones inmanentes, puesto que se presentan como indispensables en la distinción de la pluralidad en Dios. En el c. 10, santo Tomás recoge razones esgrimidas por los herejes para negar las procesiones en Dios, objeciones que podemos llamar clásicas, puesto que son incapaces de aceptar la existencia de procesiones inmanentes en Dios. Es propio del

37 "Licet ergo Deus Pater sit divina essentia, et similiter Deus Filius, ex hoc tamen quod est Pater, distinguitur a Filio, licet sint unum ex hoc quod uterque est divina essentia": SCG IV, 14. 
arrianismo, que niega la generación eterna puesto que supondría la división de la substancia divina, por tanto, cambio en Dios, que es absolutamente simple, inmutable e indivisible. En definitiva, para los arrianos, la generación en Dios destruye al mismo Dios, dividiendo la naturaleza divina. En el fondo se encuentra una concepción material de la generación, puesto que generación implica nacimiento, mutación y novedad, que es del todo contrario al ser de Dios. Recoge santo Tomás como objeción en SCG IV,10:"Como quiera que la generación que nosotros conocemos sea cierta mutación y tenga por opuesto la corrupción, parece difícil suponer la generación en Dios, que es inmutable, incorruptible y eterno". En el extremo opuesto, es propio del sabelianismo la afirmación de que el Hijo se identifica con el Padre, el cual, en la generación, se había convertido en hijo de sí mismo. Uno y otro son diversos modos de una misma persona. Por ello expresa el Aquinate la siguiente objeción propuesta por dichos herejes en el texto antes citado:

Si el Hijo no se distingue de la esencia divina, al ser subsistente de la esencia divina [...] parece resultar que el Padre y el Hijo convienen en la misma cosa subsistente. Ahora bien, la cosa subsistente en las naturalezas intelectuales se llama persona. Se sigue, pues, si el Hijo es la misma esencia divina, el Padre y el Hijo convienen en la persona.

La negación de las procesiones inmanentes impide la existencia de una real Trinidad en Dios; más aún ¿cómo afirmar la real diferencia entre Padre e Hijo teniendo como premisa irrenunciable la unidad de esencia? De nuevo nos encontramos ante el gran dilema de tratar de explicar el misterio con las más que insuficientes categorías de nuestro pensamiento que hacen relativamente sencilla la entrada en la herejía: "Es preciso que aquello por lo que se distinguen Padre e Hijo sea distinto de la esencia divina. Por lo tanto, la persona del Hijo está compuesta por dos cosas, igualmente la persona del Padre, a saber, la esencia divina y el principio de distinción" (SCG IV,10). ¿Eso distinto puede ser la relación? La respuesta parece ser afirmativa basándonos en lo indicado por Boecio: substantia continet unitatem, relatio multiplicat trinitatem. Pero tal afirmación debe ser explicada, puesto que existen razonamientos que indican la insuficiencia de la sola relación para explicar la real diferencia de Padre e Hijo sin que exista composición alguna. La primera objeción viene a decir lo siguiente: la relación necesita como accidente inherirse a alguna "substancia absoluta", por lo que la relación Padre-Hijo necesita algo que sea absoluto en lo que poder sustentarse. Si entendemos por absoluto la esencia divina entonces hablamos de dos "absolutos", cosa que es imposible según el principio de la única esencia en Dios. Si solo 
hay un absoluto no puede haber una doble relación. En definitiva, la sola relación no distingue Padre e Hijo. Como puede verse, la deficiencia está en el concepto de relación, puesto que se concibe esta como un accidente que necesita de una substancia a la cual adherirse. No es capaz de entender la relación al margen de la accidentalidad, puesto que es eterna e idéntica a la esencia divina. La segunda objeción parte de la distinción habitual en la Escolástica- de relaciones reales y relaciones de razón. ${ }^{38}$ Según el dilema propuesto, si la relación que distingue Padre e Hijo es real tendrá tal condición debido a que ambos respectos o extremos Padre e Hijo - son reales, pero si lo "real" en Dios se refiere a la única esencia divina, entonces, habría algo distinto a la esencia que los distingue. ${ }^{39}$ Pero en Dios "no hay nada que no sea su propia esencia". ${ }^{40}$ No sería verdadero Dios, termina apostillando santo Tomás. Por el contrario, y como segunda parte de la objeción, se contempla la posibilidad de que la relación no sea real sino de razón, entonces los respectos o extremos —al menos uno - no son reales sino provistos por nuestra razón. Luego no pueden ser distinguidos personalmente Padre e Hijo, cayendo así de lleno en el sabelianismo. En el fondo la objeción expresada no deja de resumirse en una sola: con la sola relación no hay manera de distinguir personaliter a Padre y a Hijo, y si hay distinción es a costa de dividir la esencia divina. Vistas estas objeciones, y tratando de ofrecer respuestas satisfactorias a estas, entramos en el capítulo que dedica santo Tomás a la relación. No podemos olvidar que el tratado trinitario en la SCG se articula en torno a las procesiones inmanentes y eternas en Dios como son generación y procesión. Según la lógica seguida al respecto tenemos que las dos procesiones fundan las cuatro relaciones: paternidad, filiación, espiración activa y procesión (espiración pasiva). Junto a lo dicho cabe recordar la máxima por la que la diferencia en Dios viene de la mano de la

38 Conviene recordar que la relación solo puede ser considerada como real cuando los dos relativos son reales, si realmente difieren entre sí. Así pues, entre relativos reales hay necesariamente una relación real. La relación entre dos entes de razón es necesariamente una relación de razón. Cf. Antonio Millán-Puelles, Léxico Filosófico (Biblioteca del Cincuentenario), Madrid, Rialp, 2002², 511.

39 Podemos ver, según nuestro parecer, cómo se señala la concepción del Verbo como una probolé - término valentiniano- por la que el Hijo se considera alius a Patre, distinto, separado, alienado, alejado, distinto en naturaleza. La objeción señala distinción real entre Padre e Hijo, que no es otra cosa que distinción de esencia, pero en Dios no puede dividirse la esencia, pues se pone en peligro la Mónada divina. Es por ello por lo que en el c. 14 apostilla santo Tomás lo siguiente al respecto de la división de la esencia divina: "Nam et verbum est divina essentia, ut ostensum est; et Deus dicens, a quo est verbum, est etiam divina essentia; non alia et alia, sed eadem numero": SCG IV, 14.

40 SCG I, 23. 
relación, pues las personas no difieren en perfección ni en esencia, ya que es única la esencia divina. Ciertamente las relaciones divinas no añaden perfección ni imperfección alguna, solamente son perfectas en cuanto que se identifican con la esencia divina. No pueden separarse una de la otra pues realmente es lo mismo, aunque la relación necesariamente ha de entenderse en Dios por la razón de que elVerbo concebido en la mente divina procede del mismo Dios que lo profiere. Santo Tomás expresa la necesaria consideración de la relación para la distinción real de las personas divinas, para ello, y como condición previa, no pueden ser consideradas accidentes en Dios sino subsistentes, con lo que se quiere decir que la relación como principio de relación no es diferente a la realidad distinguida como es la persona ni distinto a la esencia en la que subsiste. En Dios, la relación no puede ser considerada a la manera de una simple relación sino a la manera de una substancia que es la hipóstasis. Es por ello que considerando las relaciones hay varios subsistentes - personas - y considerando la esencia una sola subsistencia, un solo Dios. Así la relación se presenta como un principio de individualización en Dios (quasi individuationis principium) mediante el cual podemos distinguir en Dios las diversas personas. Según lo visto, lo propio de la relación es su"ser a", no se comprende en Dios a modo de inherencia, como"ser en". No caben inherencias en Dios, puesto que las relaciones no se distinguen realmente de la esencia divina. Es por lo que hablamos de "relación subsistente" cuando nos referimos a la persona divina, substancial en cuanto substancia divina, pues tiene como propio el ser de Dios. La relación posee la esencia completa de un modo concreto, no cabe división ni separación ni escisión.

A continuación, reflejamos una afirmación clave para el esclarecimiento del discurso de santo Tomás al respecto: aunque Dios Padre es la esencia divina, como también lo es Dios Hijo; no obstante, por el hecho de ser padre se distingue del hijo, por más que sean uno solo en razón de su divina esencia. La relación se identifica con la esencia, pero esto no quiere decir que las relaciones se identifiquen entre ellas; esta es la tesis central del sabelianismo. Las tres personas divinas, en cuanto relaciones subsistentes, se identifican con la esencia, pero la base de la distinción es la oposición entre ellas. Es esta distinción real la que está a la base de la real distinción de las personas. Estas — relaciones subsistentes- no se distinguen de la esencia divina, realmente solo se distinguen mediante distinción de razón con fundamento en la realidad; pero se distinguen realmente entre sí y se distinguen por ser opuestas. Así paternidad, filiación y espiración pasiva son lo mismo — realmente hablando- que la esencia divina, pero se distinguen realmente en cuanto se configuran como relaciones opuestas, pues la única distinción que existe en Dios 
es aquella de la oposición de relación. Nos dice el Aquinate que"la distinción de las personas ha de ser mínima" ${ }^{41}$ El Padre se distingue del Hijo por la relación de paternidad y por la carencia de origen; el Hijo se distingue por la relación de filiación; el Padre y el Hijo se distinguen del Espíritu Santo por la espiración; el Espíritu Santo, a su vez, se distingue del Padre y del Hijo por la procesión de amor con que procede de ambos. La enumeración de dichas relaciones no la encontramos en este capítulo 14, pues no debemos olvidar que la finalidad de este es refutar las afirmaciones contrarias a la generación inmanente y eterna delVerbo divino; no hacen mención, en ningún caso, a la procesión del Espíritu Santo y por ende tampoco a las relaciones por dicha procesión fundadas. Sí encontramos la mención de las cuatro relaciones en Dios en el capítulo 24, donde santo Tomás trata de explicar que el Espíritu Santo no procede solo del Padre sino que procede también del Hijo pero siendo Padre e Hijo un solo principio. Para ello se basa el Aquinate en la autoridad de la Escritura pues el Espíritu Santo es Espíritu del Hijo (cf. Rm 8,8). Se debe tener también presente que solo podemos decir que el Espíritu Santo puede decirse Espíritu del Hijo gracias a la relación de origen, ya que como hemos visto con anterioridad no existe otra distinción en Dios que aquella de la procesión de origen. ${ }^{42}$ No puede decirse que sea Espíritu del Hijo porque lo tuviese en cuanto hombre, pues leemos en Lc 4,1 que "Jesús, lleno del Espíritu Santo, se volvió del Jordán"y también en Gál 4,6 leemos" por ser hijos de Dios, envió Dios a nuestros corazones el Espíritu de su Hijo, que grita: «jAbbá!»". El Espíritu hace del hombre hijo de Dios, pero hijos en adopción. Cristo es hijo por naturaleza, el único hijo, y de este procede el Espíritu Santo. Una vez que el Aquinate toma la auctoritas Scripturae para mostrar que el Espíritu Santo procede también del Hijo; trata, con la ayuda de la autoridad de los doctores, de expresar esta verdad de fe: Atanasio, Cirilo de Alejandría, Dídimo el Ciego, Basilio el Grande, Gregorio Nacianceno, Gregorio de Nisa, el Símbolo pseudo-atanasiano. También recurre a Padres occidentales como Ambrosio y especialmente san Agustín. La autoridad de todos estos Padres es considerada para la demostración de que el Espíritu Santo viene del Hijo lo mismo que del Padre. La fe católica desde siempre enseña que la procesión del Espíritu Santo no es extraña al Hijo, más bien está íntimamente unida al Hijo. ${ }^{43}$

41 Cf. SCG IV, 14.

42 Cf. SCG IV, 24.

43 Señalamos el Concilio de Toledo III en 589; Toledo IV, en 633; Toledo VI, en 638; Toledo XI, en 675 (cf. DH, 470, 485, 490, 527). Especial importancia tienen al respecto los concilios de II Lyon en 1274 y Florencia de 1439-1445. En el primero se nos dice: "Fideli ac devota professione fatemur, quod Spiritus Sanctus aeternaliter ex Patre et 
El Filioque por el que se entiende que el Espíritu Santo procede a Patre et a Filio no solo es afirmado por la Sagrada Escritura o por la autoridad de los doctores, sino que como afirma el propio santo Tomás existen"razones evidentes" para probar el Filioque (hoc etiam evidentibus rationibus apparet). El argumento consiste en la única distinción de las personas divinas mediante la oposición relativa. Ciertamente - tal como se ha repetido- las personas divinas no pueden diferenciarse por algo absoluto, únicamente la relación o propiedad relativa puede dar cuenta de tal distinción. Mediante dicha explicación permanece incólume la unidad de esencia. Solo la oposición relativa puede distinguir las personas divinas. Junto con santo Tomás debemos afirmar que la veritas fidei hace necesaria la oposición relativa de origen, pues es la única forma que hay de dar cuenta de la Trinidad en Dios, sin caer en ningún tipo de arrianismo o sabelianismo. ${ }^{44}$ Pero ¿cuáles son estas oposiciones relativas? Podemos percatarnos, como santo Tomás expresa, de las cuatro relaciones existentes en Dios a partir de la"oposición relativa de origen". Nos dirá el santo que el Padre tiene dos relaciones, una con el Hijo (generación) y otra con el Espíritu Santo (espiración activa), mas dichas relaciones - y siendo lo siguiente de vital importancia - no fundan dos personas, puesto que no son susceptibles de dividir al Padre en dos personas. La paternidad y la espiración activa no son relaciones opuestas, no son mutuamente opuestas. De manera similar el Hijo tiene una relación con respecto al Padre que es la filiación, aunque también con el Espíritu Santo que es la misma espiración activa, ya que Padre e Hijo son un mismo principio con respecto al Espíritu. Por parte del Espíritu existe una relación con el Padre y el Hijo. Hablamos de procesión con respecto a la espiración activa. Si no existiese oposición relativa entre el Hijo y el Espíritu Santo serían una única persona como afirma el sabelianismo. Ahora bien, la oposición relativa en Dios solo puede ser considerada desde el origen, como única fuente de distinción en Dios. Cabe afirmar que la procesión del Espíritu a Filio es del todo necesaria con vistas a poder afirmar la distinción personal del Espíritu Santo con respecto al Hijo. ${ }^{45}$ En definitiva, según santo Tomás solo el origen del Espíritu Santo a Filio hace posible la relación distinta del Espíritu Santo y su ser personal, puesto que la generación del Hijo y la procesión del Espíritu no pueden ser distinguidas más que por

\footnotetext{
Filio, non tanquam ex duobus principiis, sed tanquam ex uno principio" ( $D H$ 850). Con respecto al florentino y en consonancia con el de Lyon:"Diffinimus, ut haec fidei veritas ab omnibus Christianis credatur et suscipiatur, sicque omnes profiteantur, quod Spiritus Sanctus ex Patre et Filio aeternaliter est" (DH 1300).

44 Cf. SCG IV, 24.

45 Cf. ibid.
} 
su orden y este orden implica que el Espíritu Santo procede del Padre y del Hijo. ${ }^{46}$

A modo de resumen de lo expuesto, diremos que: 1) las tres personas divinas se identifican realmente con la misma esencia divina; 2) la relación divina es subsistente, puesto que la relación es una substancia, existe en sí y por sí. La relación divina es lo mismo que la naturaleza que refiere; 3) solo desde oposición de relación según origen pueden distinguirse las personas divinas; 4) dicha oposición relativa hace posible afirmar las cuatro relaciones en Dios: paternidad, filiación, espiración activa, procesión o espiración pasiva; 5) solo diciendo que el Espíritu procede del Hijo podemos distinguirlos personalmente mediante la oposición relativa de origen. Una vez que ha expresado santo Tomás la existencia de las cuatro relaciones divinas, cabe decir que solo tres de estas relaciones fundan persona: paternidad, filiación y procesión. Solo existen tres personas en Dios. A fin de fundamentar esta afirmación central para la fe introduce el capítulo 26. En la naturaleza divina subsisten tres personas: Padre, Hijo y Espíritu Santo, siendo las tres un solo Dios. Dichas personas se distinguen solo por las mutuas relaciones: el Padre por la paternidad (también por la innascibilidad), el Hijo por la filiación, el Espíritu Santo por la procesión. Hace pues referencias a las propiedades divinas (las tres relaciones más la innascibilidad). Si a dichas propiedades, como lo "propio de cada una de las personas", añadimos la común espiración activa hacemos referencia a las notas o nociones en Dios. Responde santo Tomás a la siguiente pregunta: ¿por qué razón no existe una cuarta persona en Dios? El Aquinate no parte en su reflexión de la Sagrada Escritura o de la autoridad de los Padres, sino que metodológicamente trata de presentar la irracionalidad de la afirmación de la existencia de más personas en Dios distintas del Padre, Hijo y Espíritu Santo. Para ello se basa en la relación divina, ya que, debido a la única naturaleza divina, la única distinción en Dios solo viene de la mano de las relaciones de origen. Efectivamente, solo caben dos procesiones inmanentes en Dios: una por vía del entendimiento y otra por vía de la voluntad. Es por ello por lo que hay dos personas que proceden en cuanto que solo una puede proceder vía entendimiento y otra solo puede proceder vía voluntad. Tomando lo ya dicho en el c. 14, al ser las relaciones en Dios subsistentes,

46 Para santo Tomás no basta solo decir que el Hijo es engendrado y que el Espíritu procede del Padre, no llega al fondo del asunto afirmar solo las dos procesiones pues el origen del Hijo y el del Espíritu no se distinguen por la naturaleza que comunican sino solo por las relaciones que implican, por la referencia al origen. Cf. Gilles EMERY, La teología trinitaria de Santo Tomás de Aquino (Koinonia 44), Salamanca, Secretariado Trinitario, 2008, 404. 
cabe decir que solo hay una filiación en Dios y una procesión por vía voluntad, luego solo pueden existir tres personas divinas. ${ }^{47}$ Esto implica que Padre, Hijo y Espíritu Santo son tres personas que subsisten en la única esencia divina, que son un solo Dios y que son realmente distintas por las relaciones recíprocas según origen.

\section{LA RELACIÓN EN EL COMPENDIUM THEOLOGIAE}

El Compendium Theologiae (CT) es una obra inacabada por el Aquinate cuyo tratado De fide - primero de los tres tratados proyectados- fue realizado sobre 1265-1267. Estamos ante un escrito que recoge una nueva forma de hacer teología. Lejos quedan ya los estrechos moldes y los ligámenes impuestos por el texto del Lombardo. No nos encontramos tampoco ante una obra de corte escolástico al estilo de la propia STh ni ante el desarrollo eminentemente sapiencial y técnico de la SCG. Es importante notar que el CT se considera un escrito maduro, realizado en el pleno desarrollo del pensamiento del Aquinate. Se entiende como especialmente importante para poder apreciar la profundidad de su doctrina, la claridad y precisión de su lenguaje.

\subsection{Aspectos introductorios}

Podemos considerar el CT como una catequesis para adultos, que adopta un estilo narrativo: summa propter occupatos o compendiosa doctrina de christiana religione. La génesis de la obra parece estar en la petición que el secretario del santo - Reginaldo da Piperno - le realiza para que componga un tratado de teología con una precisa finalidad: formar en la doctrina cristiana a los laicos privados de estudios específicos, sin una base filosófica como era del todo necesaria para comprender obras como SCG o la propia STh, esta última concebida ad eruditionem incipientium. La configuración que debe poseer la obra se encuentra en consonancia a los destinatarios, se presenta como un tratado breve, con un estilo expositivo y con un contenido sapiencial. La finalidad de la revelación divina es la propia salvación del hombre, es por lo que el mismo Verbo se encarnó y se hizo pequeño para que ninguno se perdiese, sino más bien todos los hombres pudiesen participar por gracia en la gloria divina. Es el propio Verbo que es Eterno — no habla de Hijo- quien se hace carne, es decir, asume la pequeñez del hombre, pero sin abandonar su propia majestad. "El Verbo se hizo carne y habitó entre nosotros", afirma el evangelista

${ }_{47}$ Cf. SCG IV, 26. 
Juan $(1,14)$. Esta venida del Verbo está íntimamente unida a la salvación del hombre, pues el Verbo tomó nuestra pequeñez (brevitate) para mostrar la conveniencia de la redención humana. Afirma el Aquinate que"la salvación del hombre consiste en el conocimiento de la verdad". No olvidemos la frase evangélica: "lleno de gracia y verdad". El propio Aquinate en In Ion., viene a decirnos al respecto de Jn 1,14 que la encarnación del Verbo es pura gracia por la que obtenemos el más importante de los beneficios, como es el poder llegar a ser hijos de Dios. Es aquí donde se introduce la finalidad del CT: ayudar a los hombres a poder contemplar la Verdad para la propia salvación. Verdad que "se deja comprender" mediante un mínimo de conocimiento necesario para la salvación. ${ }^{48}$ Pues esta opera en tres momentos según el itinerario marcado por el Aquinate en el c.1: conocer la verdad, perseguirla como fin y observar la justicia. Para la salvación del hombre será necesario un"mínimo de conocimiento" relacionado con los artículos de fe reagrupados en el Símbolo de los Apóstoles. Se necesita también una rectitud de intención hacia Dios: es la esperanza la que nos lo asegura, esperanza que es enseñada por la oración del Padre Nuestro. Es por último necesaria la perfección de la observancia evangélica que consiste en la práctica del Decálogo, que encuentra su máxima expresión en el mandamiento del amor. Santo Tomás trata de recoger en una breve suma toda la amplitud de la revelación recogida en la Biblia. La síntesis de la doctrina cristiana que trata de realizar el Aquinate gira en torno a las tres virtudes teologales. Será necesario para ello comentar el Credo, el Padre Nuestro y el mandato nuevo del Señor. Estos son los tres "pilares" en los que ha de sustentarse toda reflexión sobre Dios, objeto de estudio en esta obra. ${ }^{49}$ Demos un paso más en nuestra exposición, no olvidemos que nuestro estudio corresponde a las relaciones divinas, pero debemos seguir cierto orden en la exposición. En el tratado De fide es donde se desarrolla la especulación trinitaria del Aquinate, dicho tratado es el primero según el orden del $C T$, orden que propone el propio santo: lo primero que se debe tratar es la fe, pues asílo presenta Pablo en 1 Cor 13,13 y así lo exige la recta razón, pues para amar y esperar lo justo es necesario conocer a quien se ama y espera.

Reduce el doctor a dos las verdades a conocer que son fundamentales para la salvación del hombre: la fe en la Trinidad y la fe en

48 "Cognitionem autem veritatis humanae saluti necessariam brevibus et paucis fidei articulis comprehendit": CT I, 1.

49 "Ut igitur tibi, fili carissime Reginalde, compendiosam doctrinam de Christiana religione tradam, quam semper prae oculis possis habere, circa haec tria in praesenti opere tota nostra versatur intentio. Primum de fide, secundo de spe, tertio vero de caritate agemus. Hoc enim et apostolicus ordo habet, et ratio recta requirit": CT I, 1. 
la Encarnación. Son estos los dos ejes en los que se resume la doctrina cristiana. Así pues, organiza los dos tratados del primer libro: Divinitas Trinitatis y Humanitas Christi. El Angélico propone este orden, primero la divinidad, posteriormente la humanidad de Cristo: "de his quae pertinent ad humanitatem Christi" como camino único "qua ad divinitatem pervenitur" (CT I, 1). Con respecto al primer tratado hay que conocer tres cosas: la unidad de la esencia, la trinidad de las personas y los efectos de la divinidad. ${ }^{50}$ El primer tratado se presenta como un largo tratado sobre la fe entendida como felicidad futura y para ello sigue el orden propio de la STh, primero habla de la unidad de Dios (cc. 3-35) y posteriormente de la Trinidad (cc. 37-67). Con respecto al orden seguido es más que conocida la crítica que se realiza a santo Tomás por el hecho de que trate con anterioridad en sus obras la unidad de Dios a la Trinidad. El problema de la originalidad de su discurso teológico con respecto a la filosofía de Aristóteles siempre ha dado que escribir a los peritos en la materia. Se ha visto la sombra de la comprensión de Dios por santo Tomás a modo de absoluto filosófico. En la actualidad parece que comienza a superarse esta idea debido a un mayor conocimiento de las condiciones históricas de su obra. Queda fuera de todo lugar la comprensión de Dios, por parte del santo, como un absoluto metafísico, puesto que una cosa es que prime la especulación como método y otra pensar que el objeto de dicha especulación es extraño a la revelación.

\subsection{La relación en el Compendium Theologiae}

El orden seguido por el Aquinate: unidad de Dios y Trinidad de personas, no debe considerarse como una primacía del primero con respecto al segundo, más bien primero vienen presentadas ciertas verdades - como que Dios existe— probadas por los filósofos mediante la razón natural. A este primer tipo de verdades le siguen aquellas no alcanzables por medio de dicha razón natural sino solo mediante la razón teológica, es decir, mediante la verdad revelada, como por ejemplo que Dios es Trino. Nos detendremos en la segunda parte del tratado De fide que considera el misterio de la Trinidad (cc. 37-67). Lo expuesto viene a ser una explicación del Símbolo de la Iglesia, siendo la expresión central de dicho Símbolo la consubstancialidad del Hijo con respecto al Padre, fórmula aceptada desde el concilio de Nicea (325) como rigurosamente ortodoxa para esclarecer las relaciones del Hijo con respecto al Padre. Santo Tomás expresa esta afirmación en CT 42 donde asevera que la consubstancialidad

\footnotetext{
${ }_{50}$ Cf. ibidem.
} 
de Padre e Hijo excluye tanto el pensamiento subordinacionista y arriano - por la división y separación de y en la Mónada divina, siendo el Hijo de otra substancia del Padre-, como el monarquianismo modalista, para el que el Logos/Verbum no es más que un flatus vocis carente de personalidad y, por tanto, de existencia propia. ${ }^{51}$ Fiel al desarrollo de la teología trinitaria occidental, santo Tomás proclama la procesión del Espíritu Santo que "procede del Padre y del Hijo" en oposición a lo mantenido por los orientales, para quienes el Padre es la única fuente de divinidad y de santidad tanto para el Hijo como para el Espíritu Santo. Así para el Angélico, "Spiritus Sanctus a Patre Filioque procedit" (CT I, 49). La metodología seguida por el santo en el CT usa el Símbolo de la fe como expresión privilegiada y sintética de los datos de fe, pero a la vez comenta dichos datos a la luz de una concesión general del conocimiento religioso. Esta es la teología que construye el Aquinate. A la luz de la consubstancialidad divina en la Trinidad y mediante las procesiones reales e inmanentes en Dios, privilegia la reciprocidad de las personas divinas en su vida íntima como en las propiedades de cada una de ellas. Centrándonos en los cc. 37-67 encontramos una división ciertamente reseñable: los cc. 37-49 giran en torno a las procesiones inmanentes en Dios: la de la Palabra como generación (37-44) y la del Espíritu a modo de amor (cc. 45-49). La explicación de ambas procesiones tiene a la base lo ya indicado anteriormente: las verdades de fe expuestas en el Símbolo. Sobre el resto de los capítulos (cc. 50-60), podríamos decir que no giran en torno a los articuli fidei, sino que son explicación de aquellos conceptos importantísimos en la teología trinitaria: relación Trinidad-Unidad (cc. 50-51); la relación intratrinitaria como única realidad por la que se distinguen las personas divinas (cc. 52-55); persona y personas divinas (cc. 56 y 60); propiedades y nociones en Dios (cc. 57-59; 61-66). Con respecto a la primera parte (cc. 37-49) el punto de partida es la ya conocida como "analogía psicológica", como especulación por la que trata de explicarse racionalmente la vida intradivina mediante la analogía de la mente humana. ${ }^{52}$ Es así como comienza el estudio de ambas procesiones en

51 Cf. CT I, 42.

52 Santo Tomás toma y desarrolla a lo largo de sus escritos la analogía de la mente del hombre como explicación de la vida intradivina explícitamente a partir de la SCG. Así cabe expresarse la teología de la procesión por la vía intelectual, propia de la generación del verbo. El intelecto posee una acción como es el entender que permanece en aquel que entiende. Dicha procesión por vía intelectual es según semejanza y puede llamarse generación en cuanto que quien genera engendra a un semejante. La procesión por la vía de la voluntad no se hace según semejanza, porque no hay en la voluntad semejanza con la cosa querida. Dos procesiones: una vía entendimiento — reservada al Hijo— otra vía voluntad — reservada al Espíritu Santo—. Cf. Luis 
Dios - cc. 37 y 45-, pues en sendos capítulos el Aquinate introduce de una manera clara y concisa el mecanismo de la mente humana como analogía de las procesiones en Dios. Mas debe partirse de una premisa clara: así afirma:"Dios se entiende y se ama a sí mismo, y el entender y el querer en él se identifican con su propio ser" ${ }^{25}$ Teniendo en cuenta la premisa indicada, desarrolla de forma concisa y clara por qué el Hijo, como Verbo del Padre, es generado vía entendimiento. Completa esta idea en los siguientes capítulos, en los que se explican diversos artículos del Símbolo con relación a dicha procesión inmanente en Dios. ${ }^{54} \mathrm{La}$ explicación de esta parte termina con la conclusión del c. 44, que expresa lo ya dicho en el c. 42, a saber: que todo lo expuesto sobre el Hijo, en lo que implica generación por la vía entendimiento, tiene su punto de partida y su resumen en la indispensable consubstancialidad. ${ }^{55}$ Dedica a la segunda procesión —en la que se asemeja aquella del Espíritu Santo con la resultante de la procesión vía amor- varios capítulos (45-49). El punto de partida es el mismo que el indicado con respecto a la primera: la consubstancialidad del Espíritu con respecto al Padre y al Hijo, ya que en Dios, ser, pensar y amar es una misma cosa. Considerando lo anterior afirma el Aquinate que "es necesario que el amado esté en quien ama cuando es amado, pues quien ama es movido de algún modo por el amado con moción intrínseca”. Asevera en parecidos términos: "Es necesario que en Dios, igual que se entiende a sí mismo, se ame a sí mismo, porque todo bien captado por el entendimiento es amable de suyo. Dios está en sí mismo como lo amado en quien ama". ${ }^{56}$ Dos son los artículos del Símbolo que son explicados en estos capítulos, a saber: "creo en el Espíritu Santo" (cc. 47-48) y "el Espíritu Santo procede del Padre y del

Francisco LaDARIA FerRer, El Dios vivo y verdadero. El misterio de la Trinidad (Ágape 19), Salamanca, Secretariado Trinitario, 20104, 336-337.

53 "Deus se ipsum intelligit et diligit. Item quod intelligere in ipso et velle non sit aliud quam eius esse": CT I, 37.

54 En el c. 40, dedicado a la forma en la que se debe entender la generación en Dios, se explica el artículo "Creo en Dios Padre y en su Hijo"; en el c. 42, el Verbo - Hijoposee el mismo ser y esencia del Padre, explicándose: "Él mismo es de la misma substancia del Padre"; en el c. 43 se dedica a expresar que el Verbo no se diferencia del Padre ni en el tiempo ni en la especie ni en la naturaleza y se explican los artículos: "nació del Padre antes de todos los siglos"; "Dios de Dios"; "luz de luz"; "Dios verdadero de Dios verdadero"; "engendrado, no creado". Vemos cómo no sigue el Aquinate el orden del Símbolo de forma continuada, puesto que ha analizado como artículo más importante aquel de la consubstancialidad de Padre e Hijo.

55 Cf. CT I, 44.

56 CT I, 45. 
Hijo" (c. 49). ${ }^{57}$ Ciertamente, en este "proceder", procesión eterna e inmanente - como varias veces hemos indicado-, se enmarca la doctrina de las relaciones trinitarias. El dogma indica que el Espíritu Santo procede del Padre y del Hijo, como también asevera que el Hijo procede del Padre. Estas afirmaciones no solo indican procedencia, sino también distinción. Precisamente porque el Espíritu Santo procede del Padre y del Hijo, nuestra débil inteligencia entiende que el primero no es ni el segundo ni el tercero, puesto que hay procedencia del Espíritu Santo con respecto al Padre y al Hijo. Lo mismo cabe decir del Hijo con respecto al Padre: es la única distinción que cabe apreciar en la Trinidad. ${ }^{58} \mathrm{Si}$ son las relaciones las que están a la base de la distinción de personas, estas deben ser reales y no de razón solo, pues existen realmente en Dios. ${ }^{59}$ Partiendo de estos presupuestos afirma el doctor que las relaciones no son accidentalmente inherentes, es necesario que sean subsistentes, puesto que realmente se encuentran en Dios y en él no pueden existir accidentes (cfr. CT I, 54). ${ }^{60}$ $\mathrm{Al}$ ser las relaciones no accidentales sino subsistentes en la propia esencia divina, las personas se distinguen por dichas relaciones de procesión inmanente (cfr. CT I, 55). Realiza el Aquinate una importante matización, a la luz de la siguiente objeción: si las personas divinas se entienden como relaciones subsistentes y las relaciones son cuatro, ¿no tendríamos que afirmar la existencia de cuatro personas divinas? Nos dice al respecto santo Tomás: "para la pluralidad de personas se requiere que las relaciones tengan una virtualidad divisoria con carácter de oposición, pues solo hay división formal mediante la oposición" ${ }^{61}$ Si bien hay cuatro relaciones subsistentes — también cinco nociones en Dios (añadimos la innascibilidad del Padre)—, debemos afirmar que solo tres de esas relaciones fundan personas en cuanto que dicen oposición: paternidad, filiación y procesión del Espíritu Santo. Hila bastante fino santo Tomás al respecto de las propiedades, nociones y relaciones en Dios. Nociones en cuanto conocemos la distinción de las personas, que no pueden ser consideradas todas propiedades stricto sensu, puesto que la común

57 Ya hemos subrayado la centralidad del Filioque en el esquema trinitario del Aquinate apareciendo en todos los escritos importantes al respecto. Cf. Super Sent. I, d. 11, a.1; SCG IV, cc. 24, 25; De Pot., q. 10, aa. 4, 5, STh I, q. 36, a.2.

$58 \mathrm{Al}$ respecto podemos leer en CT I, 52: "Sic igitur patet quod nihil prohibet Verbum Dei, quod est Filius, esse unum cum Patre secundum substantiam, et tamen distinguitur ab eo secundum relationem processionis, ut dictum est".

59 Cf. CT I, 53. Textos paralelos al respecto: Super Sent. I, d. 26, a. 1; SCG IV, c. 14; De Pot., q. 8, a. $1 ;$ STh I, q. 28, a. 1.

60 Textos paralelos al respecto: Super Sent. I, d. 33, q. 2, a. 1; SCG IV, c. 14; De Pot., q. 8, a. 2; STh I, q. 28, a. 1.

61 CT I, 60. 
espiración corresponde tanto al Padre como al Hijo. Ni todas las nociones pueden considerarse relaciones, en cuanto que la innascibilidad no es relación, sino "negación de relación" ${ }^{62}$ Afirma el Angélico: "Las cinco nociones no son cinco realidades subsistentes, sino que las tres personas son tres realidades subsistentes". Puede que a una persona le correspondan varias nociones (al Padre, $v . g$, le corresponden la paternidad, la común espiración y la innascibilidad), pero solo una hace que se constituya como persona, dicha propiedad constitutiva de persona es la propiedad relativa subsistente. ${ }^{63}$ Solo son tres las nociones constitutivas de personas, como son la paternidad, la filiación y la procesión. Estas tres nociones vemos que corresponden a las tres relaciones subsistentes e intradivinas en las que encontramos oposición. A la vez son propiedades stricto sensu, en cuanto que corresponde cada una de ellas a una sola persona, son "propiedades personales" ${ }^{64}$ La pluralidad de relaciones en Dios propiedades relativas - no puede hacernos olvidar que la esencia divina es una sola; así que es necesario que dichas propiedades sean la misma esencia divina, puesto que, como afirma el Aquinate, "las propiedades relativas son las personas subsistentes, y una persona subsistente solo puede ser, en Dios, la esencia divina" ${ }^{65}$

\section{LA RELACIÓN EN LAS QUAESTIONES DISPUTATAE: DE POTENTIA DEI}

El De potentia Dei, como obra de nuestro análisis y estudio, es un escrito cronológicamente próximo al $C T$, aunque compuesto de diverso modo. Si bien el CT tiene un acercamiento más sintético - como corresponde a un compendio-, De potentia Dei posee un carácter analítico, diremos que de disección profunda del argumento a desarrollar como es la potencia de Dios. Nos encontramos ante una obra madura. En ella, santo Tomás, a fin de afirmar sobre sólida base los planteamientos teológicos, "mete en cuestión" los datos de fe. De este trabajo quedan para la posteridad quinientas diez disputas repartidas en siete títulos: De veritate, De potentia,

62 Cf. CT I, 59. Afirma el Aquinate al respecto que, si las nociones manifiestan distinción de personas, y las personas solo se distinguen por las relaciones, luego cada noción debe "pertenecer" a una relación, de este modo la innascibilidad pertenece a la paternidad.

63 Cf. CT I, 60.

${ }^{64}$ En inusitada claridad de análisis, santo Tomás distingue las propiedades de las personas de las propiedades personales. Las segundas no son personales, en cuanto que no son constitutivas de la persona.

65 CT I, 66. No procede la comprensión de la relación como algo externo a la persona, en relación extrínseca, como afirma el Porretano.Véase al respecto CT I, 67. 
De malo, De spiritualibus creaturis, De anima, De virtutibus, De unione Verbi incarnati. Son cuestiones conducidas con animación, fruto de un diálogo activo y continuo, con adversarios de gran altura intelectual, de diversas escuelas de pensamiento y de profundas miras teológicas.

\subsection{La estructura del De potentia Dei}

Los ochenta y tres artículos del De potentia fueron desarrollados en la estancia italiana del santo entre 1259-1268. Dichos artículos se distribuyen a su vez en diez cuestiones. ${ }^{66} \mathrm{~A}$ poco que nos acerquemos a estas podemos constatar cómo de ellas cinco se refieren a temas trinitarios (qq. 2; 7-10), otras cinco atañen a la creación (qq. 1; 3-6). Nos encontramos ante una obra con un claro enfoque analítico y no sintético - como es el caso de la SCG o Super Sent._- donde el interés no reside tanto en el conjunto de la obra como en analizar en profundidad cada uno de los temas que se encuentran sobre la mesa. Uno de los objetivos fundamentales en la obra consistía en encontrar el equilibrio teológico en la afirmación de unidad en Dios y al mismo tiempo Trinidad de personas. Este objetivo, junto con su elaboración orgánica, tan claro en obras ya estudiadas, no aparece con tanta fuerza en el De pot., donde se prima la profundización de cada uno de los problemas propuestos. Pero esto no quiere decir que no exista una idea de fondo en la que puedan quedar unidos tanto el tratado trinitario como el de la creación. Es precisamente en la potentia Dei donde encontramos el nexo entre ambos tratados. La probable intención del Aquinate se encuentra en asumir la potentia Dei como clave interpretativa tanto del dinamismo trinitario como de la obra creadora de Dios, instrumento del encuentro ad intra y ad extra de la realidad divina. La potencia divina, en este contexto, significa la actitud de la naturaleza divina a comunicarse, puede leerse al respecto De pot., q. 2, a. 1, que lleva por título Utrum in divinis sit generativa potentia. En Dios, la potencia, en cuanto principio generativo, coincide con la esencia divina, pero al mismo tiempo es realizada por la persona del Padre como distinta por la relación de paternidad. Así vemos como la potentia generandi pertenece al ámbito de la esencia divina, pero al mismo tiempo se entiende "nocionalmente". ${ }^{67}$ Es importante aclarar esta afirmación, puesto que encontramos en ella un

66 Los títulos de dichas cuestiones son: I. De potentia Dei absolute; II. De potentia generativa in divinis; III. De creatione quae est primus effectus divinae potentiae; IV. De creatione materiae informis; V. De conservatione rerum in esse a Deo; VI. De miraculis; VII. De divinae essentiae simplicitate; VIII. De his quae relative dicuntur de Deo ab aeterno; IX. De personis divinis; X. De processione divinarum personarum.

${ }_{67}$ Cf. De pot., q. 2, a. 2. 
paso adelante en el pensamiento del Aquinate con respecto a escritos anteriores como puede ser Super Sent. Efectivamente, en la potentia generandi actúa un principium quo, como es la esencia, que viene asumido y determinado por el principium quod —este último de carácter personal- como es el Padre. La creación se comprende como obra de Dios en su unidad (esencia) y Trinidad. El De potentia dedica tres cuestiones al misterio trinitario cuyos temas básicos son los ya clásicos de relaciones, personas divinas y procesiones inmanentes en Dios. Del estudio de la esencia divina ( $q$.VI) pasa a los nombres divinos y de este al estudio de las relaciones y de his quae relative dicuntur de Deo ab aeterno (q.VIII). De ahí pasa a las personas, puesto que son susceptibles de expresión relativa (q. IX). Llega finalmente al fundamento ontológico de las relaciones y de las personas, como son las procesiones divinas (q.X).

\subsection{La relación en De potentia Dei}

En esta obra el Aquinate aporta un agudísimo análisis sobre el concepto de relación y, a partir de este, se aclara la fundación de las tres personas en las relaciones opuestas. Las procesiones, en cuanto que dan origen a las personas, presuponen las relaciones, ya que son solo aquellas opuestas las que constituyen las personas divinas. En Dios, relaciones y procesiones, según razón, son distintas, pero de hecho — según realidad—son la misma cosa. Analizaremos a continuación los contenidos decisivos en lo que corresponde a la relación intratrinitaria según lo dicho en De potentia VIII. ${ }^{68}$ El punto de partida sobre el cual construye santo Tomás su propuesta teológica consiste en la realidad de las relaciones en Dios, a ello le dedica de hecho el primer artículo. No es solo un axioma, sino que se constituye como una veritas fidei. Así lo afirma el propio santo Tomás en el respondeo del art. 1: "Siguiendo el sentir de la fe católica, hay que afirmar que las relaciones son reales". En Dios debe haber distinción, no solo con respecto a la creación — distinción esencial—, sino en la propia vida trinitaria, puesto que el riesgo del sabelianismo está siempre acechando. Distinción en la vida divina que no puede ser en lo absoluto, el riesgo del arrianismo también está presente. Así la distinción debe ser

68 Dicha cuestión está compuesta de cuatro artículos con los siguientes títulos: 1. Utrum relationes dictae de Deo ab aeterno, quae importantur his nominibus Pater et Filius, sint relationes reales vel rationis tantum. 2. Utrum relatio in Deo sit eius substantia. 3. Utrum relationes constituant et distinguant personas et hypostases. 4 . Utrum remota relatione secundum intellectum, remaneat hypostasis in divinis. 
en lo que corresponde a lo relativo. ${ }^{69}$ Afirma la existencia en Dios de relaciones reales y no de razón por la simple cuestión de que las personas divinas no pueden ser consideradas"tres realidades", pero tampoco"tres modalidades" de una esencia divina. En el sabelianismo el Padre sería el Hijo y el Hijo sería el Padre, concluyéndose que las personas divinas solo se distinguen nominalmente. Expresa santo Tomás la necesidad de que las relaciones en Dios sean relaciones reales pero además solo cabe que sean "operativas", puesto que en Dios — siendo puro espíritu— no pueden existir relaciones cuantitativas, la cantidad presupone la materia y ninguna materia puede haber en Dios. Las únicas relaciones que caben en Dios son aquellas operativas, pero entre estas no nos referimos a las transeúntes, sino a las inmanentes: "Es necesario poner en Dios la relación que sigue a la acción. No digo la acción que termina en algún paciente. Pues en Dios no puede darse un paciente, ya que en él no hay materia; y con respecto a lo que está fuera de él, no existe en Dios una relación real". ${ }^{70}$ Efectivamente, según el Aquinate, en Dios solo puede hablarse de relaciones reales, ya que tiene a la base una acción que permanece en el agente, como son los actos de entender y de querer. ${ }^{71}$ Manteniendo la unidad de esencia en la vida intratrinitaria, puede decirse que uno tiene su origen en el otro, como por ejemplo el Verbo de quien profiere el Verbo. Siempre que algo tiene su origen en otro debe admitirse que hay una relación real, en el caso de la divinidad, por ambas partes. Santo Tomás elabora su discurso sobre las procesiones divinas en De pot., q. 10, pero vienen introducidas en la $q .8$ que estamos estudiando. Si la relación real se sigue de una acción inmanente, las únicas acciones inmanentes en Dios son las que hemos mencionado: entender y querer. La existencia del verbum o conceptio en Dios es un dato revelado y, por tanto, es legítimo estudiar la relación entre el intellectus y la conceptio, comprendido como la procesión delVerbo de quien profiere dichoVerbo. Teniendo a la base la procesión se funda la relación real existente entre ambas partes, entre Padre e Hijo. Hemos podido advertir cómo santo Tomás intenta aclarar que las relaciones son reales, pero estas no dan lugar a tres dioses sino a un solo Dios. Las relaciones son realmente distintas en cuanto que son relaciones opuestas, pero no dan lugar a tres dioses, ya que pertenecen a la misma substancia, así las personas divinas

69 "Relinquitur ergo quod per sola relativa distinctio in divinis personis attenditur": De pot., q. 8, a. 1 .

70 Ibid.

71 Como ejemplo de acción inmanente tenemos la concepción de Verbo, aunque como el mismo santo afirma Dios es inteligente pero no sabemos el modo de serlo ni sabemos como es concebido elVerbo en Dios. Véase al respecto De pot., q. 8, a. 1, ad 12. 
no se distinguen en nada más que no sean las mismas relaciones divinas, puesto que son las mismas personas subsistentes. ${ }^{72}$ En el art. 2 afirma el Aquinate que secundum rem las relaciones son la esencia divina. ${ }^{73}$ Las relaciones divinas, aun indicando la esencia, no lo hacen a modo de esta, en cuanto que "están en", sino en cuanto que la esencia "se ordena a". Efectivamente, teniendo en cuenta la distinción relratione, la ratio de la paternidad o la de la filiación es distinta de la ratio de la esencia divina, pero las relaciones que distinguen a las personas divinas se identifican con esencia según re. También es importante señalar que la ratio de la esencia divina no se opone a las de paternidad o filiación, pero sí se oponen entre ellas en oposición relativa, constituyendo las personas divinas distintas re entre ellas. Clarifica al respecto lo afirmado por el propio doctor: "De ningún modo puede concederse que, en Dios, una cosa sea la relación y otra el ser de la esencia", ya que "en Dios no hay más ser que el de la esencia, como no hay más entender que el entendimiento". ${ }^{74}$ Deben ser claramente distinguidos los dos niveles indicados para una precisa consideración ontológica de la esencia y, a la vez, la plena afirmación de las relaciones. En el respondeo del artículo 2, santo Tomás expresa la necesidad de que las relaciones sean la substancia divina, aunque estas no son expresadas a modo de substancia, sino mediante otro modo. Para ello analiza nuestro autor el concepto de relación tal como lo presenta Aristóteles en la Metafísica V. La relación consiste en un esse-ad y no en una determinación intrínseca de la substancia inadecuadamente distinta de esta. Es necesario que el "fundamento" sea distinto de la relación real: "relatio semper fundatur super aliquid absolutum" (De ver., q. 27, a. 4, contra). Si la substancia es el sustrato de las relaciones reales, la pregunta a realizarse consiste en si existe una relación real idéntica a su propio fundamento, idéntica a una entidad absoluta. La respuesta del Angélico es contundente: en Dios la relación real se identifica con una entidad absoluta como es la propia esencia divina. Puede hablarse de "relación subsistente". En las criaturas todas las relaciones son accidentales y, por tanto, la substancia no puede identificarse con sus relaciones. En Dios, que es absolutamente simple, no puede pensarse que las relaciones

72 Cf. De pot., q. 8, a. 1, ad 6.

73 Debemos tener en cuenta lo expresado por el Aquinate: "Absoluta et relativa in divinis non differunt secundum rem, sed solum secundum rationem, ut dictum est; et ideo ex hoc nulla compositio relinquitur": De pot., q. 7, a. 1, ad 6. Podemos observar, como ocurriese en la lectura de Super Sent., que el instrumento hermenéutico usado por el Aquinate es el de la distinción relratione en lo que se refiere a la unidad y pluralidad en Dios. Cf. Ferri, Il Dio Unitrino nel pensiero di Tommaso d'Aquino, 158-159.

74

De pot., q. 8, a. 2, ad 11. 
aporten algo distinto a la esencia divina, pues no son accidentes en Dios. ${ }^{75}$ Aunque la relación no añade nada real a la esencia divina — solo según ratione-, no puede olvidarse que la relación es real. Lo propio de esta, como es la oposición y la distinción, se encuentra realmente en Dios. ${ }^{76}$ Para santo Tomás el distinctum divinum no es la substancia, sino la relación, que secundum rem se identifica con la esencia. En Dios la esencia se identifica con quien la tiene. La relación y aquello a lo que se refiere son la misma cosa, así, en la naturaleza divina, el ser distinto y subsistente son la misma cosa. Pasamos, a continuación, al estudio del art. 3, donde el Aquinate indaga sobre la correlación entre personas y relaciones divinas partiendo de la siguiente pregunta: ¿Las relaciones constituyen y distinguen a las personas o hipóstasis? Como base de su argumentación usa de la afirmación de Severino Boecio por la cual solo la relación multiplica la Trinidad en Dios. Vemos cómo, en este artículo, el Aquinate recoge las diversas controversias en lo que al asunto se refiere. Debemos partir de las soluciones inadmisibles, las cuales no admitían en Dios más que la existencia de lo concreto y lo individual y negaban la existencia de las notas personales. Afirman, en definitiva, que las personas divinas se diferencian y distinguen por ellas mismas. Frente a ellos se encuentra la autoridad de los concilios XI de Toledo, Lateranense IV y Florentino, los cuales dogmatizan sobre lo expresado por Boecio: solo la relación multiplica y distingue en Dios a las personas. En el polo opuesto encontramos otra tendencia recogida por el Aquinate, las personas son constituidas por algo absoluto, extrínsecamente son seguidas por algunas relaciones. Dice al respecto:

La esencia divina no puede entenderse como distintiva y constitutiva de las hipóstasis divinas [...] Por la misma razón, nada de lo que en Dios se predica de modo absoluto puede entenderse como distintivo y constitutivo de la hipóstasis personal. ${ }^{77}$

Se afirma la necesidad de poner lo distintivo y constitutivo de las hipóstasis no en lo absoluto sino en lo relativo. Sin embargo, existen en las personas divinas procesiones y relaciones, ¿cuál de las dos es su elemento distintivo y constitutivo? Ciertamente son realmente lo mismo, difieren según el modo de significar. Según la primera opinión, las personas divinas se constituyen y distinguen por el origen, teniendo en cuenta "qui est ab alio" y" a quo alius". Como insigne defensor de esta primera

\footnotetext{
75 Cf. De pot., q. 8, a. 2.

76 Cf. De pot., q. 8, a. 2, ad 3.

77 Cf. De pot., q. 8, a. 3.
} 
aproximación tenemos a Hugo de San Víctor, para quien las relaciones son consecuentes a los actos que los significan. El Padre se distingue del Hijo porque lo engendra, mientras que el Hijo se distingue del Padre en cuanto que por él es engendrado. Las relaciones expresan la distinción de las personas, pero no son principio de distinción. Santo Tomás rechaza esta manera de expresar el misterio y argumenta lo siguiente: "No puede decirse que la hipóstasis del Hijo se constituya por su natividad, a no ser en cuanto que su natividad acaba en lo que la constituye formalmente. La misma relación, en la que termina la natividad es la filiación".$^{78}$ Afirma, pues, santo Tomás la necesidad de que las hipóstasis divinas vengan constituidas y distinguidas por las relaciones, puesto que, siendo la paternidad la misma esencia divina $-\mathrm{y}$ aun siendo lo mismo que Dios - no es algo común a modo de esencia, sino propio. La relación de origen no puede entenderse como mera relación en cuanto que es la propia esencia divina constituyendo las hipóstasis en subsistentes y no solo en relativo. ${ }^{79}$ Distingue la hipóstasis en cuanto es relación, pero la constituye en cuanto que es esencia divina. ${ }^{80}$ La paternidad — de igual forma la filiación - hace que el Padre sea propio y distinto de las demás hipóstasis, es"subsistente en su naturaleza", en la que la paternidad, constituyendo al Padre, constituye la hipóstasis ${ }^{81}$ Lo afirmado por el santo tiene a modo de corolario aquello que se recoge en el art. 4:"Abstraídas mentalmente las relaciones, no permanecen las personas, tampoco las hipóstasis. Pues eliminando lo que es constitutivo de algo, no puede permanecer este algo". ${ }^{82} \mathrm{~A}$ poco que nos acerquemos al texto advertimos cómo recoge santo Tomás la heredad teológica, ya que en el respondeo del mencionado artículo toma en consideración la relación de origen en cuanto relacionada con persona e hipóstasis. Alude en este texto a la definición de persona "de los Maestros", a saber: persona es la hipóstasis que se distingue por alguna propiedad perteneciente a la dignidad". A las relaciones se las llama personalidades en cuanto dignificadas por alguna propiedad. Para algunos, como hemos visto anteriormente, son las procesiones u orígenes los que constituyen y distinguen las personas, por lo que abstraídas las relaciones permanecían las hipóstasis, pero no

\footnotetext{
78 Cf. ibid.

79 Cf. De pot., q. 8, a. 3, ad 8.

80 Cf. De pot., q. 8, a. 3, ad 9.

81 "Pater ergo, Deus in quantum est Deus, est commune habens naturam divinam, et in quantum est Pater, est proprium ab aliis distinctum. Unde est hypostasis, quae significat subsistens in natura aliqua, distincta ab aliis. Et per hunc modum paternitas constituendo Patrem, constituit hypostasim": De pot., q. 8, a. 3.

82

De pot., q. 8, a. 3 .
} 
las personas. Afirma el Angélico que no solo las personas, sino también las hipóstasis. ${ }^{83}$ Aclarado en la $q .8$ cómo las relaciones de origen fundan la distinción real entre las personas divinas, entra de lleno el Aquinate en el estudio de las personas divinas dando por buena la definición boeciana de persona (De pot., q. 9, a. 2), incluso aplicada a Dios, pero teniendo en cuenta que el principio distintivo es la relación. El distinctum divinum no es la substancia, sino la relación. ${ }^{84}$ La persona divina es comprendida en el De potentia:

La persona divina, formalmente hablando, significa subsistente distinto en la naturaleza divina.Y ya que esto solo puede ser relación o relativo, en su sentido material, relación o relativo.Y por esto puede decirse que la relación connota a modo de substancia, no la que es esencia, sino la que es hipóstasis; igual que la relación significa no como relación, sino como relativo, es decir, tal como se expresa con el nombre Padre, no como el de paternidad. ${ }^{85}$

La persona divina significa directamente la relación y solo indirectamente la esencia, pero no la relación en cuanto relación, sino en cuanto que significa hipóstasis. La persona significa directamente la esencia divina e indirectamente la relación, en cuanto que la esencia se identifica con la hipóstasis, pero esta en Dios viene significada como distinta por la relación, luego la relación en su significado de relación entra indirectamente en el concepto de persona: "La relación significada se incluye en línea oblicua en la acepción de persona divina, la cual no es sino un

83 Es importante para la correcta comprensión lo que aquí se entiende por persona y por hipóstasis. Comporta cierta confusión puesto que la segunda comenzó siendo sinónimo de substancia y acabó siendo sinónimo de persona. Santo Tomás hace uso de dicho término desde una pluralidad de sentidos: realidad natural, substancia, supuesto en cuanto individuo o incluso por subsistencia como res subsistens. La traducción que a santo Tomás le parece más perfecta es la de persona, aunque esta exija la naturaleza racional. La hipóstasis es pues"ser subsistente" a la que solo se le puede llamar persona si su naturaleza es racional (cf. De pot., q. 8, a. 1; q. 9, a. 1). Los tres elementos claves en la persona son la incomunicabilidad - término introducido por Ricardo de San Víctor que hace suyo santo Tomás mediante el distinctum - la subsistencia y la intelectualidad. Solo podemos hablar de persona divina en analogía con la humana. El punto clave para la correcta comprensión del asunto está en que la persona divina no viene de la esencia sino de la relación de origen. Sin embargo, la subsistencia le viene de la esencia absoluta.

84 Desde los comienzos de su enseñanza opta por la definición de Boecio, aunque afinándola con importantes acentos: "individuo distinto subsistente en la naturaleza intelectual" (Super Sent. I, d. 23, q. 1, a. 4); "subsistente distinto en la naturaleza humana", dirá en el De pot., como hemos podido ver, definición que retendrá en la STh (I, q. 29, a. 1).

85 De pot., q. 9, a. 4. 
distinto, gracias a la relación subsistente en la esencia divina" ${ }^{86}$ En definitiva, el Padre es Dios, pero no es ni el Hijo ni el Espíritu Santo, ya que hablamos de conceptos relativos. Solo en cuanto que se oponen relativamente se distinguen y son incomunicables. Pero aquello en que se diferencian, por lo que son incomunicables, que los individualiza, es lo que llamamos persona. Es por lo que la persona en Dios equivale a relación en cuanto subsistente, a relación en cuanto que se identifica con la esencia. Las propiedades incomunicables (paternidad, filiación y procesión) explican la Trinidad divina sin dividir su esencia. Para ello recurre santo Tomás a la relación de origen como lo único que es capaz de explicar la multiplicidad en la unidad de esencia. Siendo la relación idéntica a la esencia, subsiste aparte, puesto que su carácter de oposición implica la incomunicabilidad distintiva. La paternidad se opone a la filiación, aun cuando la paternidad y la filiación se identifican con la esencia divina. Así terminamos nuestra reflexión en lo que corresponde a esta obra, que sin duda es la más analítica e incluso prolija de cuantas traemos entre manos. Como ha podido constatarse, el lenguaje teológico y el análisis establecido por el Aquinate es de un altísimo nivel. La contestación a las diversas corrientes teológicas es implacable por la contundencia y por la altura de miras de nuestro autor.

\section{A MODO DE CONCLUSIÓN}

La "raigambre" teológica de nuestra categoría es también notable, pues bien pronto se hizo necesaria su introducción en el discurso teológico a fin de superar las finas elucubraciones de peligrosas herejías, como eran el arrianismo y el sabelianismo. Ciertamente, tanto los Padres como los teólogos posteriores vieron que no era rechazada por parte del dato revelado, así se convirtió en materia de dogmatización.

En la Metafísica de Aristóteles, la relación es uno de los nueve géneros de accidente. De este concepto se desprenden ciertos aspectos que son fundamentales en el tratamiento que realiza el Aquinate de las relaciones trinitarias. Las relaciones pueden ser reales o de razón, esta distinción ya viene claramente delimitada en las Enéadas de Plotino. Tal connotación tendrá como razón el que la causa o fundamento sea real o pertenezca a lo puramente lógico. La relación es un "ser" sumamente tenue; es por ello que la relación real representa una realidad de "levedad" ontológica, o con palabras de santo Tomás, un ser debilísmo e imperfectísimo (cf. SCG IV, 14). Este carácter débil se debe a que no es algo

86 Ibid. 
absoluto, incluso podemos decir que no es "algo", sino tan solo orden o referencia entre dos términos. La relación es un "hacia algo, en orden a algo". El concepto de relación no incluye en sí ni perfección ni imperfección, puesto que su ratio consiste en "ser orden hacia algo", "mirar hacia algo". Esta última característica, como hemos podido comprobar a lo largo de nuestro estudio, abre la puerta a la aplicación de nuestra categoría a la vida divina, efectivamente, si la relación no incluye perfección ni imperfección, entonces puede existir en Dios. La suma simplicidad divina solo acoge la esencia divina y la relación. Siguiendo las enseñanzas de Agustín, solo es posible aplicar este concepto a Dios si queda desprovisto de todo carácter accidental. Así solo la eternidad de las relaciones hace que estas entren en la "esfera de lo divino". Pero no solo eso, la relación es principio de distinción de las personas divinas. $\mathrm{Al}$ igual que ocurre con el homoousios de Nicea, la Sagrada Escritura no habla de una forma explícita de la existencia de relaciones en Dios, pero sí habla de procesiones en la vida divina, unos que provienen de otros. Como en una procesión real, necesariamente se da una relación entre el que procede y aquel de cual se procede, por lo que vemos que no viene ni mucho menos rechazada la idea de relación en la esfera de lo divino. La Escritura muestra claramente la existencia en Dios de tres subsistentes distintos en unidad de esencia divina. Tal distinción solo puede ser real gracias a la relación. Padre, Hijo y Espíritu Santo se distinguen solo por oposición relativa y no existe ninguna otra res distintiva. Hemos podido comprobar la centralidad que ocupa la categoría de relación en el tejido doctrinal del Aquinate. Dicha centralidad dimana a nuestro juicio de dos grandes virtualidades inseparables que posee nuestra categoría. En un primer momento, decimos que expresa de forma privilegiada la unión intrínseca entre unidad de esencia y pluralidad de personas en Dios. Ayuda a la comprensión de la vida intradivina. En un segundo momento, no menos importante, la relación entra de lleno en la definición de persona, ya que se define como"relación en cuanto subsistente en la esencia divina". Podemos afirmar que dichas virtualidades no pueden ser separadas, como tampoco pueden serlo realmente personas, relaciones y esencia divina, salvo en nuestro intelecto, según nuestra razón. Una novedad que introduce el Aquinate en su doctrina viene a ser que las relaciones, en cuanto subsistentes, son la misma realidad. Cada una de estas es "subsistente en la naturaleza divina", lo que quiere decir que es"non aliud quam natura divina". La identidad de relación y esencia implica al mismo tiempo que las personas divinas tienen su ser en la esencia divina y también que la esencia única no subsiste realmente sino en las relaciones, en las personas divinas. Estamos de acuerdo con la tesis 
de G. Greshake para quien Tomás de Aquino es el primero en afirmar que lo propio de la relación no es solo un ser-hacia-otro, sino también un ser-en. Pero el ser-en de la relación divina en identidad real con la esencia divina. ${ }^{87}$ Este es el gran avance que introduce santo Tomás en la teología trinitaria. En otro orden de cosas cabe decir que el estudio de cualquier aspecto de la teología trinitaria en santo Tomás debe pasar por la categoría de relación, puesto que sin atender a lo relativo en Dios mutilamos el mensaje revelado en la Escritura, que habla de tres en la divinidad. En definitiva, hemos tratado de constatar con este trabajo que la relación trinitaria encuentra una sistematización sin igual en la obra de santo Tomás de Aquino y en especial en la Summa Theologiae, que hemos dejado fuera de nuestra reflexión para centrarnos en los escritos quizás menos conocidos.

87 Cf. Gisbert Greshake, El Dios Uno y Trino. Una teología de la Trinidad, Barcelona, Herder, 2001, 148-149. 